Illinois State University

ISU ReD: Research and eData

Theses and Dissertations

4-10-2014

\title{
A Moral Panic? A Content Analysis Of Prominent Newspapers And Their Portrayal Of Tik Addiction
}

Chiara Keune

Illinois State University, clkeune@ilstu.edu

Follow this and additional works at: https://ir.library.illinoisstate.edu/etd

Part of the Criminology Commons, and the Criminology and Criminal Justice Commons

\section{Recommended Citation}

Keune, Chiara, "A Moral Panic? A Content Analysis Of Prominent Newspapers And Their Portrayal Of Tik Addiction" (2014). Theses and Dissertations. 177.

https://ir.library.illinoisstate.edu/etd/177

This Thesis is brought to you for free and open access by ISU ReD: Research and eData. It has been accepted for inclusion in Theses and Dissertations by an authorized administrator of ISU ReD: Research and eData. For more information, please contact ISUReD@ilstu.edu. 


\title{
A MORAL PANIC? A CONTENT ANALYSIS OF \\ PROMINENT NEWSPAPERS AND THEIR \\ PORTRAYAL OF TIK ADDICTION
}

\author{
Chiara L. Keune
}

103 Pages

August 2014

The rise of tik (methamphetamine) in the Western Cape of South Africa was an issue of contention for government and health care officials. Tik is the label given to the homemade crystal methamphetamine in South Africa, and the primary substance of abuse for many addicts seeking help. This paper sets out to examine tik from a moral panic perspective to understand if tik is an actual threat or a moral panic phenomenon. Two prominent newspapers were examined using content analysis. The Cape Times and Cape Argus were sampled to understand the social construction of tik. A moral panic is simplyan episode of widespread social fear, which is in disproportion to the actual threat. These episodes usually appear out of nowhere and fade just as quickly and require a mass media capable of supporting it. Measuring two indicators, hostility and disproportionality of the moral panic framework, and comparing the reporting of tik with empirical data, it was found that there is no evidence of a moral panic surrounding tik. The findings did not suggest hostility or disproportionality in terms of the media reporting. 


\title{
A MORAL PANIC? A CONTENT ANALYSIS OF PROMINENT NEWSPAPERS AND THEIR PORTRAYAL OF TIK ADDICTION
}

CHIARA L. KEUNE

\author{
A Thesis Submitted in Partial \\ Fulfillment of the Requirements \\ for the Degree of \\ MASTER OF SCIENCE \\ Department of Criminal Justice Sciences \\ ILLINOIS STATE UNIVERSITY \\ 2014
}




\section{A MORAL PANIC? A CONTENT ANALYSIS OF \\ PROMINENT NEWSPAPERS AND THEIR \\ PORTRAYAL OF TIK ADDICTION}

CHIARA L. KEUNE

COMMITTEE MEMBERS:

Ralph A. Weisheit, Chair

Cara Rabe-Hemp

Dawn Beichner 


\section{ACKNOWLEDGMENTS}

I would like to express my sincere gratitude to the following people for the help and support they gave me during the completion of this thesis.

Dr. Ralph Weisheit, chair, for his never-ending assistance, guidance and interest in my topic. For always having time to listen, being ready to help and provide much needed motivation.

Dr. Cara Rabe-Hemp, for challenging me to streamline my writing processes, providing valuable insight and reminding me to 'Stand on the shoulders of giants'.

Dr. Dawn Beichner, I would not have gotten to Illinois State without you, it has been a pleasure being a CJS All-Star.

Dr. Jackie Schneider and the Criminal Justice Department for letting me have this Grad school adventure.

Last but not least my mom, Jessie for encouraging and supporting my dreams, her prayers, and love.

Jeremiah 29:11

C.L.K. 


\section{CONTENTS}

\section{Page}

ACKNOWLEDGMENTS

TABLES

\section{CHAPTER}

I. INTRODUCTION 1

II. $\quad$ LITERATURE REVIEW 6

Moral Panic Perspective 6

$\begin{array}{ll}\text { Definitions } & 7\end{array}$

Moral Panic $\quad 9$

Cohen, Folk Devils and Moral Panic 11

Policing the Crisis 14

The Next Model: Goode and Ben-Yehuda 15

$\begin{array}{ll}\text { Drugs and the Media } & 18\end{array}$

LSD in the 60s 19

Crack Craze 21

Meth 22

$\begin{array}{ll}\text { III. HISTORICAL PERSPECTIVE } & 28\end{array}$

IV. RESEARCH DESIGN 37

Research Objectives and Aims 38

The Decision to Use Content Analysis $\quad 41$

Sampling 43

Units of Analysis $\quad 43$

Coding Category $\quad 44$

Code the Material 45

V. DATA ANALYSIS AND DISCUSSION 50

Discussion Research Question One $\quad 62$

Discussion Research Question Two $\quad 70$ 
VI. RECOMMENDATIONS AND CONCLUSIONS

Practical Recommendations $\quad 72$

$\begin{array}{ll}\text { Conclusions } & 73\end{array}$

$\begin{array}{ll}\text { REFERENCES } & 75\end{array}$

APPENDIX A: Pilot Study, Code Book and Collection Sheet 80

APPENDIX B: Final Study Code Form and Collection Sheet 93 


\section{TABLES}

Table Page

1. Primary Tik Abuse 1997 a to 2010 a (\%) (Pludderman, et. al.,2010) 32

2. Number of Tik Patients in WC Treatment Centre's (Nyabadza \& HoveMusekwa,2010)

3. The Number Of Articles Containing The Word Tik 2007-2012 51

4. List of Descriptors for the Qualitative Examination of Tik 54

5. Qualitative Descriptors of Tik Addicts 58

6. Previous Scares Frequency Chart $(\mathrm{n}=63)$

7. The Most Common Words From Previous Scares Found in this Study 62

8. Article Tone over Time 68

9. Article Tone, Patients in Treatment Trends 2007-2012 69 


\section{CHAPTER I}

\section{INTRODUCTION}

"The compelling quality of drugs as objects, as emotional images, and as symbols leads us to fixate upon them"

-D Manderson, 2005: 800

Breaking $\mathrm{Bad}$, is the hit TV series that has captured the interest of audiences worldwide. It featured the extreme adventures of Walter White, a New Mexico chemistry teacher turned crystal meth cook. The show has been hailed as the greatest television drama to grace the screen (Bridgland, 2013). But in the Western Cape, South Africa, where nearly 3 million, mainly mixed race people live, there is no TV glamour about methamphetamine or tik, as it is known. Long before Breaking Bad seized audience's attention; other equally dramatic scenes were playing out on the Cape Flats (a vast, low lying flat area, Cape Town's largest residential quarter). What appears to have thrust tik onto the national stage was the story of Ellen Pakkies, who murdered her 20 year old tikaddicted-son. Pakkies was a woman who snapped, and in a move that would not be out of place in an episode of Breaking Bad, strangled her tik addicted son Abie, after he threatened her life one too many times. Pakkies is reported as saying; she took a rope and strangled him and watched him die. He looked so peaceful, not the stranger who had been harassing and threating her life 
for the past six years (Samodien, 2008). After strangling her son to death, Pakkies surrendered herself to the police. Her case was brought before the magistrate, who ruled that she was the victim in this instance and handed out a three year suspended sentence and 260 days of community service (Bridgland, 2013). Pakkies was not the first victim of tik, nor would she be the last.

News stories of abuse, death and decay do not fit with the overall picture presented of the Western Cape. It is one of nine provinces in South Africa, each with their own legislature, premier and executive council, distinctive landscape, population, economy and climate. The Western Cape lies at the Southern tip of Africa, and is one of the most beautiful regions attracting the lion's share of foreign tourists. Centuries of trade and immigration have created a population with genetic and linguistic links to different parts of Europe, South East Asia, India and Africa. This diversity in cultural background provides a distinct demographic profile that's very different from the national pattern. Cape Town being the Mother City is an important port with one of the fastest growing economies in South Africa, alongside Gauteng. The Western Cape contributes $14.5 \%$ to the national economy with a GDP valued at R291-billion (SouthAfrica.Info, 2013). While it may contribute a huge chunk to the economic status of South Africa, the Western Cape also ranks high in other statistics. The Medical Research Council found that nearly $98 \%$ of all tik addicts seeking help in South Africa originate from the Western Cape, with the highest number of users among those who are under 19 years old. The United Nations Office on Drugs and Crime report (2013) singled South Africa out as one of the biggest players in the manufacturing of tik. This was an issue of concern because as of 2012 South Africa had become the leading manufacturer of tik in the southern African region 
(World Drug Report, 2012) and is fast becoming a major exporter of one of the most destructive drugs on the market. Captain Johan Smit former narcotics squads cop, was quoted as saying "tik is big business" (Behr, 2011:1). Drug busts are described like "a scene from a bad movie" (Behr, 2011:1), except unlike the movies or glamour of TV shows, this is a death trade. If drugs like tik don't kill people, they certainly ruin their lives.

There are reasons why tik is prominent in specific areas of the Western Cape. It is no surprise to South Africans that the areas where tik is more prevalent are the same areas that are politically marginalized and economically excluded. There is a problem with tik as a primary drug of abuse in the Western Cape, affecting the social and moral fabric of society. According to Moscovici's theory of Social Representation, meaning is "created through a system of social negotiations from discursive productions rather than being a fixed and defined thing" (Caputo, 2013:446). Mass media therefore has a role in the formation of communication and will be a reflection of the community it represents. This is in agreement with Jamieson and Campbell who write that "the news media is a pervasive and forceful persuader, with the ability to shape perceptions and to influence belief and attitude" (2006: 119). This is especially important when it gets to issues of criminal justice as we see regarding tik.

There is an abundance of literature within South Africa, which deals with the increase of patients being treated for tik addiction, the effects of tik on the pregnant female as well as the risky sexual behavior of tik addicts and the prevalence of HIV/AIDS. Substance abuse poses a major risk of increased child neglect, domestic abuse, crime and violence. It also undermines sexual, physical and mental health and 
impacts negatively on people financially. It's important that empirical studies are undertaken to evaluate these costs and provide solutions to the problems associated with substance abuse. The Provincial government of the Western Cape has legislated prevention, treatment and aftercare programs in terms of the National Drug Master Plan (2006-2011) and the Prevention of and Treatment for Substance Abuse Act of 2008. And while empirical research is important and provides some understanding of the issue, it lacks personal accounts that reflect the social dynamics of the communities that are affected. Factual, mathematical models and empirical studies do not always bring in a humanistic perspective. The manner in which journalists find and depict news is a reflection of the community. "There is an interrelationship between media, society and criminology...it involves the interaction of journalist, sources, and audiences that coexist within a diverse and eclectic cultural and social system" (Barack, 1994: 6).

The purpose of the study is to explore the perceptions of tik in the Western Cape utilizing content analysis of two newspapers, studying the phenomenon from a moral panic perspective. Research (SACENDU, 2007) indicates that compared with other provinces, the use of tik as the primary drug of abuse is highest in the Western Cape (35\%) as compared to other provinces (e.g. Eastern Cape at 5\%). Data from the Medical Research Council found that the proportion of persons under 20 years old for the treatment of tik related issues increased from $4 \%$ in 2003 to 57\% in the first half of 2007 (SACENDU, 2007). To understand if this problem is an actual threat or a reflection of a moral panic, two prominent newspapers will be sampled from 2007 to 2012. The articles pertaining to tik related abuse and use will be analyzed using content analysis and two of 
the five indicators of moral panic will be measured. In order to infer elements of moral panic two research questions will be answered:

Research Question 1: What types of words are used in The Cape Times and Cape Argus to describe tik and tik addicts? Are these words similar to the words used in previous moral panics (e.g. LSD in the 1960s, crack in the 1980s?).

Research Question 2: Is there a change in number of articles and their tone and does this correspond to a change in the number of patients in treatment for methamphetamine?

In order to answer these questions, the LexisNexis database will be used to source articles from two prominent newspapers, The Cape Times and the Cape Argus. Information will be entered into a coding sheet, which conceptualizes the elements of moral panic and will allow a pattern of word usage to emerge that can be compared with other moral panic research studies. This form of study will also allow the researcher to compare articles with the available empirical data available. 


\section{CHAPTER II}

\section{LITERATURE REVIEW}

\section{Moral Panic Perspective}

There is no question that methamphetamine has received considerable scrutiny in the media. The issue is whether that attention is justified or has been exaggerated and distorted. Is the level of concern justified or can it more accurately be described as reflecting what has been called a moral panic? The term moral panic was coined in the early 1970 s to describe British media messages that announced an increase in crime rates and the establishment of specialized police units to deal with the alleged problems (Young, 2009). The term entered common vernacular following the publication of Stanley Cohen's book Folk Devils and Moral Panics (1972). In his book Cohen was influenced by labelling theory (Becker, 1963) and the ways in which deviance is less about people's behavior and more about what society deems or labels normal and deviant. In his initial work he focused on the youth culture that was gaining popularity in the post- war period and the way in which society responded to the behavior of these mostly male youth groups. It was seen as moving from traditional subculture theory, with an emphasis on the reactions to the seaside skirmishes in the early 1960s between members of two youth subcultures: Mods and Rockers. It was a fusion of structural and labelling theories. According to this view the same deviant behavior would be treated 
differently according to its timing and place. To fully comprehend the thesis outlined by Cohen, moral panic and folk devils need to be defined in some detail.

In this chapter, I will review Cohen's ground breaking study of moral panic, along with Goode and Ben-Yehuda's work that expanded Cohen's theory with the introduction of five indicators that refined the moral panic framework summarize the drugs and media research and apply the moral panic model to the problem of methamphetamine in the Western Cape of South Africa.

\section{Definitions}

According to Cohen $(1973: 9 ; 2002: 1)$ moral panic is defined as:

(1) A condition, episode, person or group of persons emerges to become defined as a threat to societal values and interests;

(2) Its nature is presented in a stylized and stereotypical fashion by the mass media;

(3) The moral barricades are manned by editors, bishops, politicians and other right-thinking people;

(4) Socially accredited experts pronounce their diagnoses and solutions;

(5) Ways of coping are evolved or (more often) resorted to;

(6) The condition then disappears, submerges or deteriorates and becomes more visible. Sometimes the object of the panic is quite novel and at other times it is something which has been in existence long enough, but suddenly appears in the 
limelight. Sometimes the panic passes over and is forgotten, except in folk-lore and collective memory; at other times it has more serious and long-lasting repercussions and might produce such changes as those in legal and social policy or even in the way the society conceives itself.

A better understanding of moral panic is provided by Jenkins (1999:4) "an incident of widespread social fear that appears seemingly out of nowhere and that grows in the space of a few month or years then fades to nothing". Furendi (1994:1) writes of moral panic as being newspaper headlines that "continually warn of some new danger which threatens our health and happiness". Additionally Furendi (2005) describes moral panic as a psychological process underlying the politics of fear, law and order agendas, witch hunts, pogroms and other forms of oppression. Simply put moral panic is: A process whereby a real or imagined, social problem becomes highlighted or manufactured. This problem may be seen as a threat to traditional values and morals. The mass media and other channels of communication may "stereotype this problem, possibly exaggerating it and creating folk devils in the process" (Rohloff, 2008:69).

Folk devils become the "other" that the rest of decent society felt we need protecting from (Rohloff, 2008: 69). The folk devils were people who identified with Mods and Rockers and as such were perceived as a threat to the current social order. Moral panics cannot be generated unless there appears to be a degree of concern over a real or imagined threat. There also needs to be the perception that "government organizations are either unwilling or unable to alleviate the problem" (Rohloff, 2008:71). 


\section{Moral Panic}

Applying the concept of moral panic to an issue requires addressing several questions. How does a panic occur and take hold, what are the indicators, and who is involved? Cohen looked at the reaction of five segments of society: "the press, the public, agents of social control or law enforcement, lawmakers and politicians and action groups" (Goode and Ben-Yehuda, 2009:29). Two additional factors that can be said to characterize moral panic: the creation of folk devils and the development of the disaster mentality. This folk devil is a deviant, someone who is part of the wrongdoing, and whose actions are considered harmful to society. Steps should be taken to neutralize their actions so that they may return to normal. The drama of moral panic emerges in the development of disaster mentality, which includes: predictions of impending doom, over reaction, institutionalization of threat, rumor, false harms and mass delusion. The concept of moral panic rests on disproportionality in the degree of public concern over the behavior itself, the problem it poses or the conditions it creates. Disproportionality utilizes empirical information, figures or numbers, which are often times exaggerated. Finally, a defining characteristic is that moral panics are volatile, erupting suddenly and almost as quickly subsiding or disappearing. Folk devils are the young, poor, and powerless emblems of social change and are the scapegoats of life in an uncertain world. Folk devils are seen as enemies of society by their virtue of their being a serious social problem and therefore deserving of public hostility and or punishment (Burns and Crawford, 1999).

Usually short lived, moral panics exaggerate a problem, symbolize it in certain groups, predict its future then conclude or change. They can be said to be anxieties about 
particular human subjects or practices. Many times they are generated by the state or media, picked up by interest groups and social movements, or vice versa. There is the dual role of expert and media critic, in bringing about a moral panic: the former testifying to its existence and the other sensationalizing it. This makes the risk of a particular panic seem like a new, terrifying part of everyday life. The media plays a role in producing moral panic, by sensationalizing a problem and then presenting it as a threat to the social order. This causes the public to have an exaggerate fear of the problem which, the media then fuels with inflammatory writing.

The prime impetus for panic, is real or imagined events used to "evoke moral outrage and generate action" (Bromley, Shupe \& Ventimiglia, 1979:43 as cited by Goode \& Ben-Yehuda, 2009: 137). This is typically an anomaly that has become known as a commonplace event. The perception that this event has become commonplace has been known to generate calls for action from the public (Goode \& Ben-Yehuda, 1999). In many cases more than one attention-grabbing story in the space of a short time may become connected as a theme indicating a growing threat. There is an energy and fascination bordering on enjoyment. In this regard a moral panic, like crime, can be seductive. Police pursue the deviant while the media thrives on controversy created by the event, and the public avidly follows the outrage. Often the deviant event is galvanized and sometimes reconstituted.

Moral panics do not occur in a vacuum. They are particularly likely to emerge in a society that is experiencing tension due to changes in cultural and moral regulation. If enough people find these changes disturbing, there is a greater propensity for moral panic. The voice of moral panic is found in the amount of media attention an issue is 
given (Cohen, 1972; Goode \& Ben-Yehuda, 1999). The proposal of legislation can be an indication that a moral panic has occurred (Goode \& Ben-Yehuda, 1999). Moral panics give voice to salient and sometimes unspoken social values. Academic examples of moral panic describe the media and authorities' exaggerated reactions to or the 'collective mistake in understanding' of the behavior of a particular group or cultural identity In the middle of a moral panic the public will "feed on a stylized and exaggerated depiction of a new enemy while the media, officials, pundits, and politicians champion traditional morality" (Linnemann, 2010:99). Experts then sweep in, pronounce a diagnosis and provide solutions to calm fears and sway public sentiment.

The 'problem' is often depicted as one to which the poor are particularly susceptible. Young (2007: 42) wrote "it cannot be an accident that the stereotype of the underclass with its idleness, dependency, hedonism and institutionalized irresponsibility with its drug use, teenage pregnancy and fickleness represents all the traits which respectable citizens suppress in order to maintain their lifestyle".

\section{Cohen, Folk Devils and Moral Panic}

Stanley Cohen blazed the trail in work on moral panic theory (1972) in his work that characterized the public reactions to the fighting of two youth groups in 1960s Britain. Cohen used the labelling theory of deviance. According to this view the same deviant behavior would be treated differently according to its time and place. So the question then becomes, who decided when to apply the deviant label?

The process of labeling will have consequences. A person learns to identify who they are based on interactions with others, but more importantly with significant others. 
An individual whose behavior has come to be labelled deviant may start to conform to this label in a way that confirms this label. As such, this labeling process exaggerates the deviance. If this theory were correct the Mods and Rockers, two opposing youth groups as depicted in the media should have begun to identify as opposing groups. The difficult part was proving this effect. Cohen found instead that there was a clear pattern in the way the society responded to the Mods and Rockers. He wrote: "societies appear to be subjected every now and then to periods of moral panic" (Cohen, 2002:1). Cohen was in this sense able to provide a distinctive contribution: an account of the key agents in moral panic and a model of its overall trajectory. This can be called a "processual model of moral panic” (Critcher, 2003:1129).

Within this processual model, four sets of agents vital to the development of moral panic were identified by Cohen: the mass media, moral entrepreneurs, the control culture and the public. One of the most important of these was "understanding the role of the mass media in creating moral panic and folk devils" (Cohen, 1973:17), because of the way the media produces images of deviance and the deviant. There are three processes involved in the production of deviance and deviants. First the exaggeration of who said or did what along with added distortion. Second the consequences of failing to act are predicted and third and finally symbolization, the words Mods or Rockers signal threat. In this process the Mods and Rockers become folk devils installed by the media. The media is focused on events and people, disrupting social order. In order for the media to interpret such events the journalists employ 'inferential structures' unspoken explanations of what the behavior is like, who commits this behavior and why it happens. 
The second group 'moral entrepreneurs' would be the people or groups advocating to rid the society of threatening behavior. Cohen is interested in their motivation and tactics (Critcher, 2003). Those with institutional power make up the third group 'social control culture'. These would be the police, courts, and politicians. With the context of moral panic they will diffuse concern from the local to national level as they are sensitive to the proof of widespread deviance.

All control measures advocated are done in the name of 'public opinion', the fourth agent. Cohen used individual and group discussions to research how the public could be both accepting and skeptical of media images. The complexity between these four groups aided Cohen in defining the problem and its remedies.

A consequence of moral panic is usually a change in law or its enforcement. After the scuffles put forth by the media between the Mods and Rockers a drug law was strengthened and another was introduced as a direct response. Panic usually happens in part to reaffirm society's moral values. In the early 1970s the process became more visible, as Cohen suggests moral panics are endemic "because society will continue to produce the deviants which it then condemns" (Cohen, 2002:172).

Stanley Cohen showed how moral panics about Mods and Rockers in the 1960s arose through mass media commentary about their deviant, hooligan and delinquent nature (Cohen 1980). These Mods and Rockers were portrayed as affluent, ungrateful youth who exhibited violent and destructive behavior (Cohen, 1980). As a result social control agents responded to these images. Police for example, would identify problem youth by their hairstyles or clothing and would then proceed to stop search and fine or 
arrest these deviant youth. Cohen demonstrated how information can construct and perpetuate deviance and how measures of social control respond to these developments. Particular kinds of individuals are labeled as dangerous to the wellbeing of society because they have deviated from the agreed upon norms of the general good. The question one must ask is, "why this conduct is deemed deviant and whose interest does it serve?" (Cohen, 1973:12-13) Another influential aspect of Cohen's thesis is that moral panics are generated by the media or by particular interest groups. Cohen stressed the media as an 'especially important carrier and producer of moral panics'.

Cohen's work made several important points; the first is that every moral panic had its scapegoat, the 'folk devil' onto whom public fears and fantasies were projected. The moral panic must have an object. It must be about something. The underlying cause of moral panic was the cultural strain and ambiguity caused by social change. The object of moral panic was not so much the Mods and Rockers or the post war affluence but rather the sexual freedom they represented.

\section{Policing the Crisis}

Hall and his co-authors were able to utilize Cohen's model in the 1970s to describe a crime wave in Britain between the years 1972-1973. The coverage of the crime wave peaked in '73, and saw three youth given rather lengthy detention sentences. The entire length of this moral panic was just thirteen months, but was able to produce long term effects that impacted society. In their article about policing the crisis, Hall and his co-authors describe the muggings which fit Cohen's model almost perfectly as a “struggle over hegemony, helping justify a wider law and order campaign” (Hunt, 
1997:636). According to their research the statistics did not indicate an increase in street crime, and muggings did not denote a problem. Rather they connoted a threat from young males who happened to be Black. They were able to elaborate on all four aspects of the media and its role in the formation of the mugging panic.

Hall and his coauthors agreed that the media was among the powerful forces that shape the public views about issues, but they also argued that moral panic relating to law and order may typically originate in statements made by the police and the judiciary which are then amplified by the media. In this sense the media does not create the news so much as it reproduces and sustains the interpretations of it. This would then imply consciously or not that "the media functions as an instrument of state control" (Hall et. al., 1978: 220-2)

\section{The Next Model: Goode and Ben-Yehuda}

Erich Goode and Nachman Ben-Yehuda published Moral Panics: The Social Construction of Deviance in 1994, an expansion of Cohen's theory, by providing indicators of the moral panic. A rather different model to Cohen's of the 1960s, their model set out to deal with the concern surrounding the definition of a social problem. In the review of theoretical and empirical studies in the constructionist tradition they were able to supplement and identify five criteria they believe should be present in order for moral panic to occur.

Goode and Ben-Yehuda are said to describe the second theory of moral panic as the 'elite-engineered model' (Hunt, 1997). This second theory is developed more by Stuart Hall and colleagues in Policing the Crisis: Mugging, the State and Law and Order 
(1978). Their model of moral panic was designed to fill the gaps in Cohen's use of the term. Cohen implied that "the media created the news and images which lent the cognitive basis for the panic" (Hunt, 1997:634).

Goode and Ben-Yehuda's account of the 'elite engineered' model is that the ruling classes deliberately and consciously create a moral panic about an issue not really harmful to society as a whole in an attempt to divert attention from more serious problems. They then identify a third part of the theory, which they term the 'grass roots model'. According to this theory politicians and the media cannot fabricate concern where none existed initially, and as such moral panics must be founded on some genuine public concern. This is a more bottom up theoretical approach to moral panic.

The original model drew mainly on symbolic interaction and labeling theory in relation to deviant behavior. In a broad sense, the concept refers to the creation of a situation in which exaggerated fear is manufactured about topics that are seen to have amoral component. These panics have to create, focus on, and sustain powerfully persuasive images of folk devils that can serve at the heart of moral fears. Such highly overstated and imaginary fears have typically focused on gang activities, youth, illicit drugs, pornography, and prostitution. The original model seemed to assume a somewhat monolithic culture. So this begs the question, what happens to moral panics in multicultural societies where morality itself is constantly contested and negotiated?

Research focused on the media as a creator and spreader of fear have focused on moral panics as an important mode for creating and sustaining cultures of fear. Moral panics are not characterized by flight or fright responses as the panic part is merely a 
metaphor, and has nothing to do with physical panic reactions. Rather moral panic is characterized by speeches, preaching, debates, legislation, law enforcement priorities, agenda setting and the like. The focus here is moral issues. The question of how people react to cultural and economic change is what lies at the heart of moral panic theory. It can be said that moral panic is the struggles for moral hegemony over interpretations of the legitimacy (or lack thereof) of prevailing social arrangements and material interests.

Goode and Ben-Yehuda (1999) refined the theory by providing a list of indicators that should be present before it may be concluded that a moral panic has occurred. The first being a legitimate level of concern over certain behavior, second hostility linked to the category of people responsible for this behavior. These individuals are seen as evil, the folk devils defined by Cohen in his work. Third, the public needs to come to a consensus that this behavior is a threat to the moral fabric of society. Fourth, disproportionality-the perceived threat should be removed, far removed from any objective measures of seriousness. Fifth and finally, volatility: the moral panic must erupt suddenly and will subside just as quickly.

Over the years the Mods and Rockers were forgotten, and within a few years new folk devils emerged to replace them. Recently the term 'folk devils' is more likely to be applied to vulnerable figures such as people with AIDS, unmarried mothers or the more contestable phenomena such as the Satanic abuse of children than to aggressively deviant or antisocial groups such as the Mods and Rockers. Most far reaching in the thesis was the remark that "the processes by which moral panics and folk devils are generated do not date" (Hunt, 1997:632). Sindell (1990:29) applied the concept of moral panic to other historical periods on the assumption that Cohen's model is "applicable over time" and the 
only pre requisite for a moral panic being the existence of a mass media capable of transmitting it.

A way to understand the social construction of the meth scare is to apply the moral panic conceptual framework.

\section{Drugs and the Media}

The mass media is the primary source of public knowledge about deviance and social problems, including the problem of illicit drugs. The media serves three functions: 1) setting the agenda, 2) transmitting the image and 3) breaking the silence. The mass media decides who or what is deviant based on public consensus and opinion. These images are transmitted, and a claim is put forth. It is this claim making, which adds to the rise of moral panic.

Moral panics about drugs have been seen for over one hundred years; consisting of the evil pusher and the vulnerable user. New substances are continually added to the list. Heroin, cocaine, marijuana, amphetamines, LSD, designer drugs, synthetic drugs, and crack cocaine have all been included among the substances that have been featured in mass media headlines.

Moral outrage and repression have been cast on those blamed for the "demon drugs" (Renairmen and Levine 1997:5 as cited by Linnemann, 2010). The associated blame betrays assumptions about race, class and gender based inequalities. Major drug panics, from the LSD craze of the 60s to the crack craze of the 1980s also saw the rise and fall of three Ice Ages of meth-centered panics. 


\section{LSD in the 60s}

Currently the manufacturing, distribution and possession of Lysergic acid Diethylamide (LSD) is illegal. It was banned by the Federal Government in the late 1960s under a haze of controversy and scrutiny (Goode, 2008). This drug was labeled promising in the research and medical fields while others labeled it dangerous.

Nonetheless it was the focal point of many heated debates during its time. Most scholars agree that the way in which LSD was covered by the media, the hysterical commentaries, and the public scandal along with the rapid legislative changes, make it a 'folk devil', worthy of being called a 'moral panic (Goode, 2008). Some moral panic scholars provide justification that social problems such as LSD do not readily emerge as social threats because they are dangerous, but rather because of efforts to present them as dangerous (Ben-Yehuda 1986, Victor, 1998).

According to Cornwell and Linder (2002) many elements of moral panic were present at the height of the controversy over LSD and as such the moral panic model is a promising and appropriate approach for understanding the social reaction to LSD. It was viewed as a moral panic because the concern it stirred up was disproportional to its objective threat. The case of LSD also reveals the "gullibility of the media and the public in believing outlandish, false, or exaggerated claims" (Goode \& Ben-Yehuda, 2009:80). In 1966, the chair of the New Jersey Narcotic Drug Study Commission called LSD the "greatest threat facing the country, today...more dangerous that the Vietnam War" (Brecher et. al.1972:369). That was as Goode and Ben-Yehuda (2008:80) wrote, a "reckless claim made by a responsible person but one that would carry some sort of credibility". The media ran with these claims, and did not do much background 
verification into the drug itself. Goode (2008) submits that this threat was more panic driven than materially real.

What kind of threat was LSD? It was a threat to the hegemony of the middle working class, work ethic, morality and world view with threats of cosmic revelations and an alternative world view to those who ingested LSD. This notion of otherworldliness that LSD propagandists were selling was an affront to the moral standing of good society. This is what was so feared. This made for good news; it was a fantastic media story: the fact that this drug would turn young people into free loving hippies and psychedelic zombies (Jenkins, 1994). The term zombies was commonly used in the synthetic drug panic as pointed out by Jenkins (1994) and would be another indicator of a drug panic surrounding LSD and its subsequent banning in the 1960s.

The main element that's almost always the basis for moral panic is disproportion. This can be seen in atrocity stories that lack fact or when a presumed threat is raised to boiling point. Hyperbolic words and phrases are used to describe what is happening, words such as "pandemic", "epidemic", "scourge", "terrifying”, "pervasive”, 'highly addictive". These words should be seen as a tip off that the possibility of a moral panic is at hand but feelings of fear are out of proportion to the objective threat and harm (Reinarmen and Levine, 1997:18-51).

Even though new drugs may come along the rhetoric used in moral panic is "timeless" (Jenkins 1999:4) and simply requires a mass media capable of transmitting it. 


\section{Crack Craze}

In the 1990s a prominent group of policy advisors that included former drug czars William Bennett and John Walters along with Criminologist John Dillio produced research that heralded a coming crime wave rising from the inner city ghettos that would crash down heavily on White middle class Americans. They argued that inner city poverty and the degradation of family would collide at the intersection of crack cocaine and demographic conditions to produce 'morally poor' children or 'super-predators'. These super predators would rain "unparalleled violence on urban ghettos and spill over into White America" (Bennett et al., 1996:13). In constructing this crisis the authors tapped into White America's racist fears. They exploited the young Black criminal, and their construction of the super predator helped exclude these men spatially and socially. The moral panic over crack resulted in the political campaigns that emphasized the "war on drugs'. This policy came into play when crack was not even a popular drug of choice at the time. Another feature of moral panic being rapid implantation of legislation, the resulting policy implications, that came out of this particular moral panic indicate how pervasive and far the ripple effect of a panic goes. Over the years the crack epidemic and the super predator may have faded from collective memory, but the consequence are still glaringly visible. Taking a cue from previous drug panics the media again heralded a new 'as-of-yet unrivaled' epidemic. In 2004, New York Senator Chuck Schumer warned in a rather Orwellian manner "its 1984 all over again". This statement read as follows:

"twenty years ago, crack was headed east across the United States, like a Mack Truck out of control and it slammed into New York hard, because we just did not see the warning signs $[\ldots]$ and if we don't remember our history we will be 
doomed to repeat it, because crystal meth could become the new crack" (as cited in Linnemann, 2010:97).

Most striking of the growing meth panic is it is not allegedly concentrated in poor inner city neighborhoods, but is particularly attractive to rural and suburban America.

\section{Meth}

For many meth is a new drug that is seemingly taking the world by storm and adding to the infamous list of already popular drugs. The New York Times Magazine wrote an article in 2005, which reiterated this point- meth is a "new drug" (Sheff 2005: 45). In reality Meth is not a new drug. The vision or idea that meth is a new drug is rather flawed. Typically meth is a term that has been applied to homemade substances manufactured at rural levels. The production method - amateur versus commercial- is what typically separates meth from its finer produced equivalents. Yet meth in general is not portrayed as a commercial drug at all. Using the five criteria outlined by Goode and Ben-Yehuda (1994) the third moral panic surrounding meth was dissected by Armstrong in 2007. His study looked at the discussion surrounding meth as a new drug. In studying the social responses to meth users Armstrong found a response that was harsh in nature and impacted negatively on the user. This study Moral Panic over Meth, brought to light the differences in manufacturing techniques that make up amphetamines of which meth is a part. Armstrong shows two sides to the meth user, the common demonized user and the celebrated figures. The only difference being one group had meth prescribed over the counter and the other group from the local cook. The conclusion was that meth is not in fact a new drug but rather this is another wave of panic and that the official response to 
the social condition is out of all proportion to the alleged threat. A brief summary of the study is broken down into the five criteria.

Concern is the first criteria in the moral panic catalogue. It is a heightened level of concern over the behavior or issue. Applying this to meth on a national level, the Combat Meth Act was introduced by Member of the Senate in 2005 and later by the House Members (The Orator 2005a; 2005b as cited by Armstrong, 2007). Armstrong proposes that the volume of articles on InfoTrac and LexisNexis support the importance of meth as a 'social threat', the study comprised an examination of the InfoTrac and LexisNexis database on meth related articles and compared the percentages with drug abuse related visits to the emergency departments (ED) between 1994 and 2002. In 1996 and 2001 ED mentions Meth comprised 1.2\% of total drug related mentions. In 1996, meth was a topic of only $6 \%$ of the InfoTrac articles and only $3 \%$ of the LexisNexis articles. In 2001, these percentages increased to $27 \%$ of InfoTrac and $17 \%$ of LexisNexis.

Hostility, this is the second indicator and targets individuals who are seen as evil folk devils. This hostility is also aimed at people responsible for the threatening behavior. The distinction between who uses meth as opposed to who use (prescription) amphetamines is predicated on a pre-supposed distinction serving the interests for the defiler (Armstrong, 2007). There is a certain hostility aimed at people who use nonmedical home produced meth and not toward people who use amphetamine when the only difference between the two drugs is the production method. Children diagnoses with ADHD, individuals who suffer from sleep disorders, and some US Air Force pilots, are just some of the people who legally use amphetamine. Beside these common folk, J. F 
Kennedy, Jean Paul Arte and Pete Rose the baseball player are all known to have used amphetamines (Courtwright 2001, Chass 2002).

Yet the media is focused on the demonization of meth and its users, and its interpretations are far removed from children, politics, politicians and philosophers. The language that describes meth users separates them from normal, ordinary citizens and labels them deviants. They do not fit within the bounds of 'middle class propriety'. Meth is no respecter of class, race or geography as more countries globally report rising numbers of users. Indeed, there seems to be a relationship between meth and rural poverty as meth is often times labeled 'the poor man's cocaine'

Consensus, there should be substantial or widespread agreement or consensus at least to a certain degree, that this threat is real, and serious. This feeling should be fairly widespread, though the proportion of people who feel this way need not be universal or even make up the majority (Goode \& Ben-Yehuda, 2009). The source of consensus is usually the print media. This consensus is achieved through declarations of meth production as hazardous to the environment and as putting children in harm's way. This is a powerful message as almost everyone cares about the environment and welfare of children. These types of messages usually appeal to the masses, and would ensure that enough people agree on the issue.

Disproportionality is the most vital element of the five criteria. In short, the term moral panic implies that 'the public concern is in excess of what is appropriate if concern were directly proportional to objective harm' (Goode \& Ben-Yehuda, 2009). It is almost the foundational aspect of moral panic. Given the pervasive prescribing of over the 
counter amphetamines and the addictive properties of meth if they are in any way comparable to the media portrayals then it should be that meth labs appear on every block in the USA.

Volatility this element indicates that a moral panic erupts suddenly and then subsides (Welch, Price \& Yankey, 2002:18). In describing moral panic as a volatile and relatively short lived phenomenon does not mean that when the panic erupts, structural and historical antecedents do not already exist. It is merely implying that these phenomena will have an evanescent quality that is unlike other panics (Goode \& BenYehuda, 2009).

Using these criteria it is possible to identify three periods of moral panic regarding methamphetamine in the Unites States. The first moral panic with meth at its center was in 1962. It was the result of meth users who had started to inject their fix. Later in this panic, they upgraded their high by combining amphetamine and heroine to form a drug cocktail. These habitual users became known as speed freaks (Brecher, 1972).

The second moral panic around meth was detailed by Philip Jenkins in 1994. He introduced this second panic as the 'Ice Age' in reference to ice as a synonym for meth. His study was a chronological examination of meth in the media from 1989-1991. This short lived panic was in response to the alleged increase in smoke-able meth or 'ice'. This panic found its way into congressional hearings during October 1989 and January 1990 and seemed to be a repetition of the first panic, and a repetition of the 'crack panic' of 1986. The concern was not sustained and diminished sharply within a few months. This 
'Ice Age' highlighted how quickly an issue can be thrust into the spotlight under a moral panic context. This Ice Age was largely localized in Hawaii and still managed to get national level coverage through multiple factors. In the account by Jenkins, there were similarities in the way the media approached both the crack issue and the meth issue. Simply put the experiences of crack made it easy for the media to represent meth as part of the same problem. The explosive growth in popularity, addiction in high numbers and the destructive images were put forth in claims that usually employed stories of atrocities, backed by statistics and studies. Jenkins (1994:9) states that all the elements that existed to create an Ice Age, are still around and are likely to lead to future "ephemeral drug panics" and that this 'Ice Age' is likely to "be repeated in various forms".

After reviewing the moral panic surrounding drugs in America, some things are worth noting. First, the timeless quality of the moral panic framework, the concepts can be applied to many social problems and can be applied to many different cultures and places. Also calling something a moral panic is not to deny its existence, and the reaction to it is not delusion or fantasy, or a trick by those in power. Two related assumptions require some attention. First, that the attributions of the moral panic label means that the thing's extent and significance has been exaggerated (compared with other more reliable, valid, and objectionable sources). Second, the problem is exaggerated when compared with other more serious problems.

To summarize, when public passion and outrage generates enough momentum to affect emotions and judgment, and when a person or thing is regarded as responsible for disrupting the collective notion of moral order. The behavior needs to be corrected. 
Sometimes these episodes will have all the defining features of moral panics. Other episodes will only have portions of the defining features of moral panics. 


\section{CHAPTER III}

\section{HISTORICAL PERSPECTIVE}

The purpose of this paper is to take these outlined elements and apply them to a different country that appears to be in the midst of a moral panic, South Africa. There is no evidence of studies in South Africa that have addressed the issue of meth as a moral panic. Observing other moral panics centered specifically on drugs in the United States, this study will extrapolate the conceptual framework of moral panic and apply it to the methamphetamine problem in the Western Cape of South Africa, a different country with its own set of moral standards to examine how moral panic fits the issue at hand.

In South Africa, methamphetamine is known on the street as tik. Tik is the drug that appears to have taken the Western Cape of South Africa by storm. For many people, drug abuse and addiction is lost among the stories of violent crime, hijackings and political corruption that are found in many South African news reports. Hidden beneath the beauty that is the Western Cape with its beaches, historical landmarks, rich cultural history and the ever present Table Mountain, few people see the dark and troubled world that is part and parcel of tik addiction (Nyabadza, Njagarah, \& Smith, 2012). Tik is the street namof the crystalline powder methamphetamine that is placed in a light bulb and 
heated with a lighter; the crackling noise it makes (tik-tik) gave rise to the name tik, South Africa's very own blend of methamphetamine (Myers \& Parry, 2003).

Primarily stereotyped as a "white trash" drug in the United States (Weisheit \& White, 2009: 17), in reality methamphetamine does not discriminate. Since its introduction to the global market, methamphetamine has only grown in use and popularity (Weisheit \& White, 2009). Within South Africa tik was first documented in the latter part of 1997 , where the primary tik abuse for this period was $0.1 \%$. Research found that the province of the Western Cape is the hardest hit. Pludderman, Parry, Bhana, Harker, Potgieter, Gerber and Johnson (2010) documented this by outlining the percentage of Tik abuse from 1997-2010. These numbers increased dramatically peaking at $43 \%$ in 2006 (Pludderman, et al., 2010).

It's unfortunate that few research studies that focus on life in South Africa cannot leave out the legacy of apartheid when discussing a social problem and how even twenty years into democracy the laws implemented during apartheid still affect life and the social construction of reality for many communities. During apartheid there was a system referred to as the "dop" system, dop being a colloquial Afrikaans word referring to alcohol (South Africa History Online, 2013). Essentially, for centuries workers on wine farms in South Africa were paid partly or entirely in alcohol. This system was officially outlawed in the 1960s but remained an unofficial part of the wine farm practice well into democracy (Humanitarion News and Analysis, 2009). During this time, there was the implementation of the Group Areas Act, which segregated people based on race in a separate development plan. The Medical Research Council in 2009 estimated that alcohol dependence was at $31 \%$ in the Western Cape which is $10 \%$ higher than the National 
average (Humanitarian News and Analysis, 2009). Not only does the Western Cape report high figures in that category, but also in the category of Fetal Alcohol Syndrome (FAS), with the reported highest rate of FAS in the world (Daley, 1999).

Daley (1999) continues to write that the level of drinking and the role it played in people's lives has contributed to it becoming an integral part of their culture. In many cases, social, cultural and situational factors will influence the choice of the addictive object (Oksanen, 2013). Culture plays such a huge role in the addictive object, and it's rather fascinating when dealing with South Africa: being a country that is so racially and ethnically diverse means that South Africans are able to share in a multitude of cultural traditions. The Western Cape in particular is different in that the majority of people living in that region are descendants of Blacks, Whites, Malay slaves imported in the 17th century, and the Khoi-Khoi, and San peoples who are indigenous to South Africa (South Africa History Online, 2013). Meaning that the colored people of the Western Cape have assimilated aspects of culture, history, and traditions from numerous parts of the world into their own mix that is specific to that region.

This study is important as it allows for an examination of the public's perceptions of tik. It is also important considering the high rate of alcohol addiction, and the research that points to the use of poly drug substances in addiction (Myers \& Parry, 2003). Can it be said that tik is moving up to join alcohol on its infamous pedestal? Empirical research shows that the drug is on the rise. Is this just a phase in the Western Cape or does tik have the potential to become an undesirable part of the culture? (Parry, Myers, \& Pludderman, 2004). 
This research will get past this gap, as several studies have demonstrated a correlation between media coverage and public opinion on issues of importance (Lang \& Lang, 1991). Each culture will deal with its association to alcohol and drugs differently; these culturally accepted images and symbolic interactions are usually circulated via the media (Oksanen, 2013). Other research on tik also highlights the importance of social and cultural dynamics of communities affected by tik, as these are considered important factors at the core of the tik epidemic dynamics (Nyabadza \& Hove-Musekwa, 2010). There is already a political movement to ban the advertisement of alcohol on a national level within South Africa, further strengthening the cultural aspect of alcohol and the subsequent high levels of alcohol dependence, as integral to many South African cultures. The perception of the community surrounding tik use and its users will be instrumental in gaining insight into why this drug has gained popularity, why it can be said to be part of the culture, and why treatment is not a high priority for the Western Cape (Parry, Myers, \& Pludderman, 2004).

Moral panics or drug scares still require a general consensus or near enough consensuses within a society or community to establish the severity and seriousness of an issue and this is typically achieved through mass media. There is a natural cycle when it comes to moral panic, it builds, peaks and eventually disappears entirely (Cohen, 2002). The first mention of tik in the news was in the latter part of 2003, and the current study will examine the coverage of tik in prominent South African newspapers to see if the reporting of tik matched the empirical works that tabulate the percentage of tik abuse for each year. This will help provide an understanding as to whether the tik wave in the 
Western Cape is part of a drug scare or is a legitimate concern being broadcast to the community.

There are a number of empirical research studies that highlight the growth in addiction rates especially among children of a school going age (Zapata, Hillis, Marchbanks, Curtis, \& Lowry, 2008). Many of these studies point to substance abuse associated with the drug, from its chemical makeup to what makes it an attractive drug to women (Weisheit \& Wells, 2010). Perhaps one of the most important is the work by Pludderman, Dada, Parry, Bhana, Bachoo, Perreira, Nel, Mcweba, Gerber and Freytag (2010:3) where they broke down primary tik abuse for the years $1997 a$ to $2010 a$ by percentage. This breakdown enables one to see the availability of tik in South Africa and its rapid increase over short periods of time. [The years were divided into 6 month sections, $a$ denoting the first 6 month (January-June) and the $b$ denoting the last (JulyDecember)].

Table 1: Primary Tik Abuse 1997a to 2010a (\%) (Pludderman, et al., 2010)

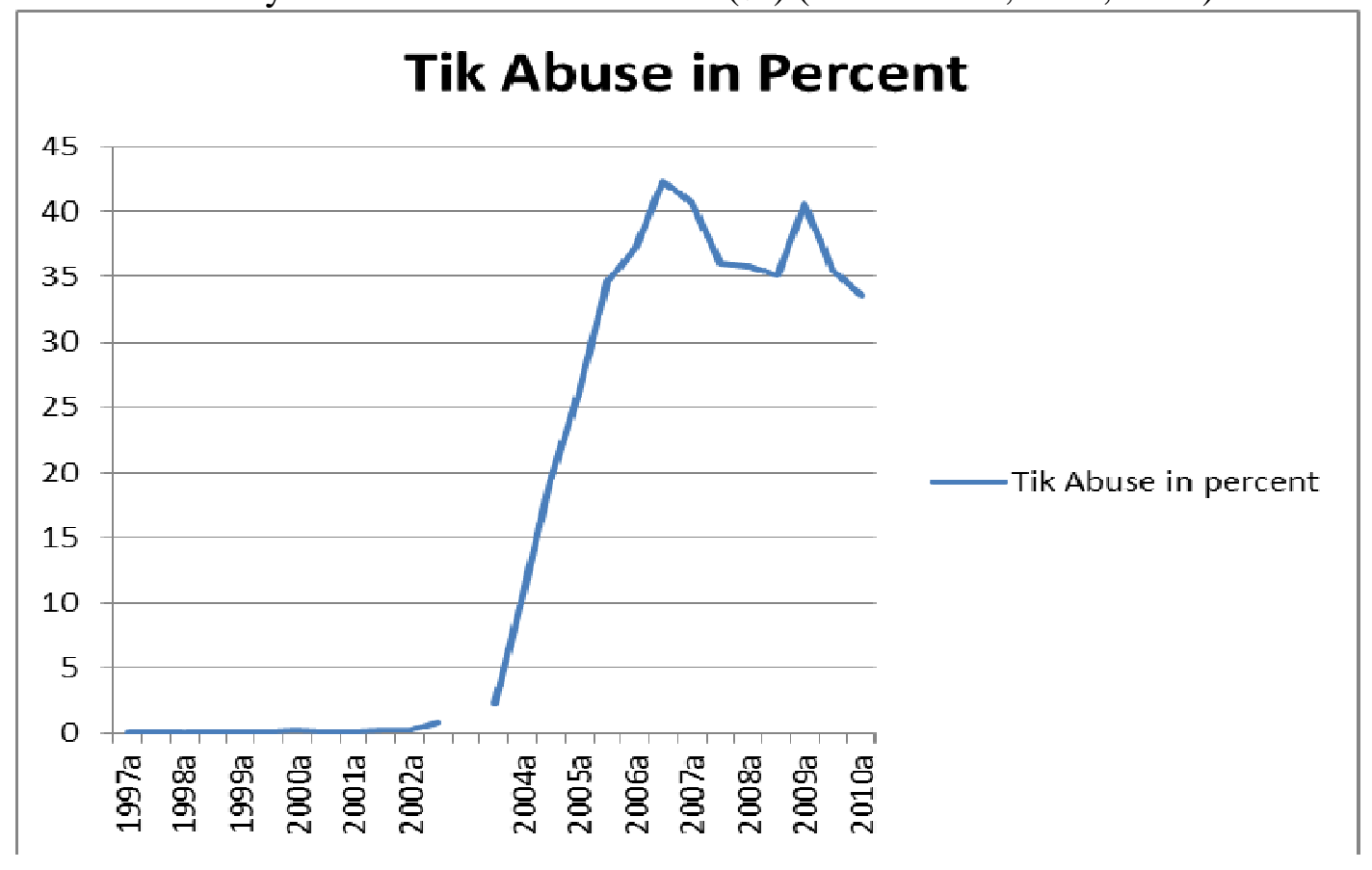


Table 2 shows the number of patients that have entered treatment centers for tik addiction in the Western Cape (Nyabadza \& Hove-Musekwa, 2010). This table shows the rather sharp increase in treatment demand, this empirical research further strengthens the argument that the burden of drug abuse is greater in the Western Cape when compared to other provinces in South Africa. These two tables can be compared and they can mirror the trends from abuse growth to entry into treatment centers. These research studies are mainly all mathematical models and very few try to examine Tik addiction from a community perspective. As with table 1, $a$ represents the months January through June and $b$ represents the latter months July through December.

Table 2: Number of Tik Patients in WC Treatment Centers (Nyabadza \& Hove-Musekwa, 2010)

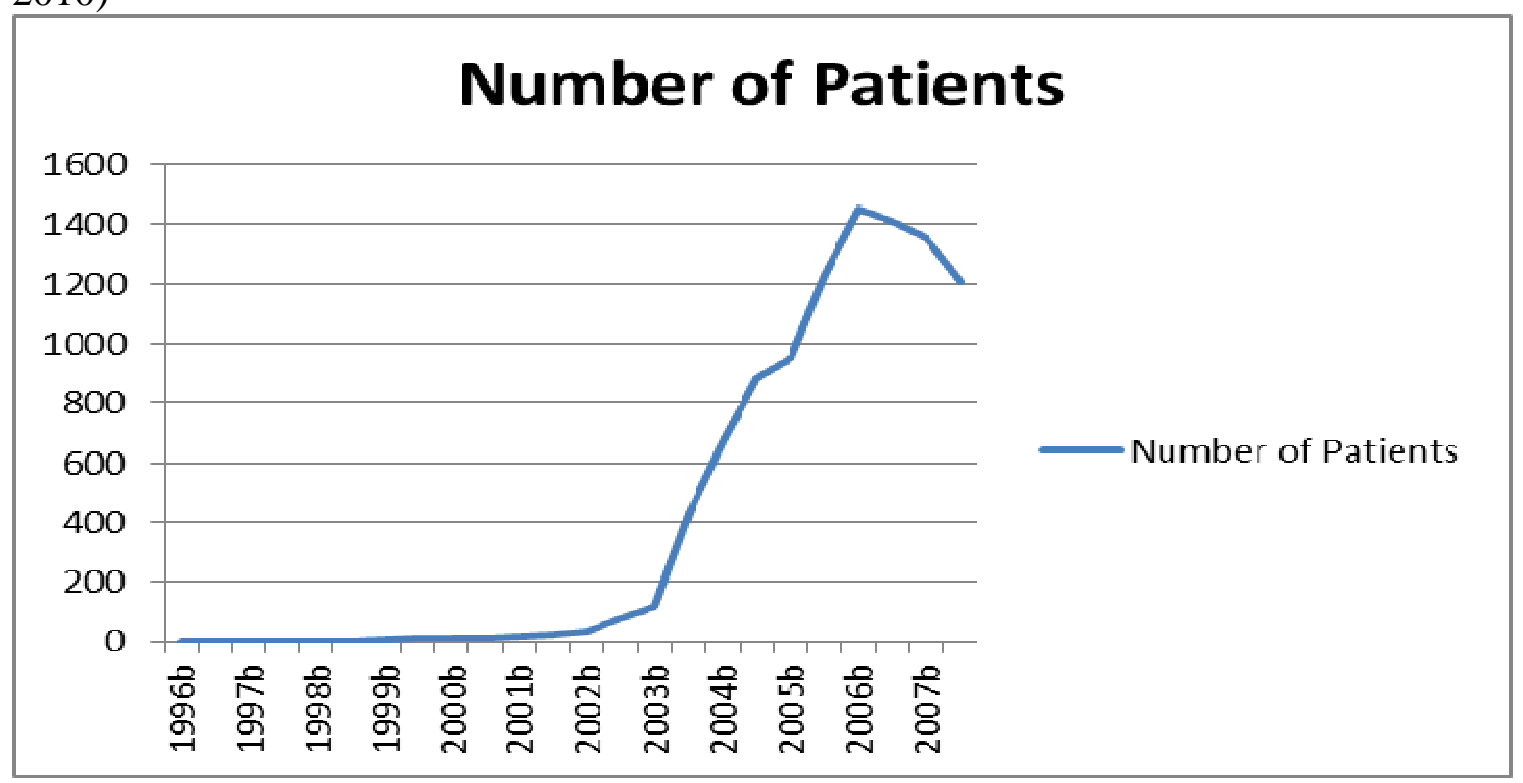

These empirical studies show that more people have been turning to tik and probably more will because it's easy 'user-friendliness' and relative cheapness in the Western Cape (Myers \& Parry, 2003). Most reports place tik at between R20-R30 per straw, which would be about $\$ 2-\$ 3$ per straw in the current exchange rate. On the street 
of Cape Town, the tik is packaged and sold in drinking straws, the generally inserted into a light bulb or 'lolly' to be smoked (Nyabadza, Njagarah, \& Smith, 2012). Since more people are turning to tik to get a cheap high, it only makes sense that the community reflects these changes in the object of addiction as per the theories outlined above. And while research has noted the effects of the drug, very little has been done on how addicts are portrayed and the influence of the media in the popularity of the drug. These gaps in the literature show that this current study can be instrumental in how policy is enacted at a community level to better target the issue of tik in the Western Cape. By understanding how addicts are portrayed, there is a better understanding on how to approach the problem. As medical practitioners and criminal justice researched continue to study the impact of tik on people within the Western Cape it would be interesting to study the portrayal of tik addicts and the way in which this new drug is reported within the media.

The South African Community Epidemiology Network on Drug Use reports that in the second half of 2012 over 3,000 people were treated for drug abuse in 26 treatment centers in Cape Town. Of the 3,000 users surveyed 56\% reported tik as their primary drug of addiction, with alcohol coming in second at $22 \%$ and then marijuana in third place at 22\% (Nichols, 2013). This same report, documented a decrease in heroin admissions, placing tik as the reigning drug of choice for many addicts. The academic literature on tik notes that drug abuse and the burden of drug use are greater in the Western Cape Province when compared to other provinces in South Africa (Pludderman, A., Dada, S., Parry, C., et al. as cited by Nyabadza \& Hove-Musekwa, 2010) . These patterns of drug abuse in the Western Cape are driven largely by a pattern seen in the Cape Town drug scene. Drug abuse spiked in Cape Town in the past years due in part to 
the in-migration of people from neighboring provinces, unemployment, and poverty as well as an increase in gang related criminal activity in the Cape Flats (the low lying, flat area situated to the southeast of the central business district) (Nyabadza \& HoveMusekwa, 2010).

In 2003, Ted Leggett of the Institute for Security Studies wrote an article entitled On the Tuk Tuk Express: Has Methamphetamine Hit the Cape Flats? This article outlined the drug market in 2003 within South Africa. This article placed the primary manufacturing of drugs in Gauteng, and named Gauteng as the distribution hub for major drug networks. This was interesting because majority of tik busts were occurring in the Western Cape some 500-600 miles away. Specifically these busts were clustered in Mitchells Plain, an areas usually associated with gangs and drugs. Leggett also included information pertaining to addicts getting help. In the second half of 2002 there were only three tik patients receiving treatment in Cape Town, but by the first half of 2003, thirtyfive people were getting help in treatment centers for tik addiction. Leggett pointed out that at the time of submitting this article, crystal meth, soon to be called tik, was a 'recent arrival on the scene'. As Leggett put it, methamphetamine was an "ideal tonic to prepare gun men for a hit, removing inhibitors, sharpening senses and fueling aggression" (2003:35). Leggett's article may be the ideal starting point in an examination of tik in South Africa. His article had three rather interesting points near the end. First he noted that crystal meth has the potential to be manufactured locally, but it's "...imperative this potential is not realized" (2003:35). Second, he assumed that because the gangsters found the highs extreme and its effect received mixed reviews, this would prevent it from becoming an issue in South Africa. Third, he saw that for some it could become a niche 
market and law enforcement should keep an eye out. Leggett compiled the article in 2003, when tik was fairly new and not a perceived threat. When did this change, can these changes be seen, and when did this morph into proportions that have lead the media to dub it 'The devils drug' (Franschoek Life, 2007)?

This research examines print media coverage of tik related offenses from a moral panic perspective. Close to twenty years after America experienced its third Ice Age of meth moral panic, South Africa may be experiencing its first. The core principle from Cohen's work was the notion of 'timelessness' this idea that a moral panic can occur at any time, as long as there is a mass media capable of supporting it (Sindell, 1990: 29). By plotting the emergence, rise, and progression of tik and utilizing Goode and BenYehuda's (1999) model of the five indicators is it possible to view the creation, rise, and fall of an apparent moral panic. Content analysis is a remarkable tool for the examination of such an issue. 


\section{CHAPTER IV \\ RESEARCH DESIGN}

Over the past 20 years or so content analysis has been the fastest growing primary message-centered methodology (Neuendorf, 2002). Originally introduced by Lasswell (1972) to study propaganda, it is described as "a technique which aims at describing with objectivity, precision, and generality what is being said on a given subject in a given place at a given time" (Lasswell, Lerner \& Pool, 1952:34). According to McNamara (n.d., 9) content analysis should involve an examination of multiple variables, and the primary units of content analysis are messages expressed as words or phrases. Newbold (2002) proposes three steps for content analysis 1) selection of media forms, 2) selection of issues or dates and 3) sampling of relevant content within those media. The sampling should be done in an objective way to ensure reliability is maintained in the study.

McNamara (n.d.) also notes other key text elements commonly studied, such as adjectives, both positive and negative, when used in descriptions. These will give a strong indication of a writer's attitude. Visual imagery within the text and context factors, such as credibility of sources quoted, all affect the meaning derived from the text. In many cases a message presented by an expert will generally outweigh a non-expert opinion. 
Research studies show that mass media has a significant impact and effect on public awareness, perceptions and even consumer behavior (McNamara, n.d.). Much of the information in the above sections points out that the Western Cape is probably the main area associated with the abuse and distribution of tik. This led to the need to select media based on geographic location: the Western Cape. After picking a location, a form of media needed to be selected to use in the content analysis. After a careful examination of the press in South Africa, two newspapers were selected. The Cape Times and the Cape Argus, both newspapers were selected because they are published in English, are available on the LexisNexis database, and can be accessed online. To be included in the search articles had to discuss tik, crystal meth or methamphetamine, within the geographical area of the Western Cape.

\section{Research Objectives and Aims}

The purpose of this research is to examine tik from a moral panic perspective and all five indicators should be measured. Ideally one would address these issues but this is beyond the scope of this study. The focus of this research is to determine when the tik problem peaked, and how it was framed. In addition to this, two research questions will address issues relating to the moral panic part of tik addiction. These two questions are important to the study as they address the issue of hostility and disproportionality respectively.

Hostility, these levels should be increased toward the 'folk devil' in question; there should be a clear divide, the "us" and "them". This dichotomization includes stereotyping: "the way in which the enemy is depicted will contribute to the subsequent 
demonization of that enemy" (Goode and Ben-Yehuda, 2009:38). By the stereotyping of these folk devils, either by age, race, presumed socioeconomic status, physical appearance, in other words their profile. This is also a measurable indicator, what does the media say about tik and tik users, what kind of language is used to describe these people? Are there the same types of words used today that were used during the LSD panic of the sixties? Those words were an indication to Reinarman and Levine (1997) that a moral panic was at hand. Labeling is a process of hostility, the names the media bestows onto addicts and the drug starts the process of dividing the population. It encourages the hostile behavior that separates the good from the bad, the "us" and "them", good decent people, from the deviant "other" (Goode \& Ben-Yehuda, 2009: 38).

Disproportionality, this term implies that public concern is in excess of what is appropriate if concern were directly proportional to objective harm. Goode and BenYehuda argue that disproportionality is a measurable term and not, as their critics call it an "...empty meaningless concept" (Goode \& Ben-Yehuda, 2009:40). They suggest that only by knowing the empirical nature of a given threat one can determine the degree of disproportionality. And, since the very concept of moral panic rest on disproportionality, if one cannot determine disproportionality one cannot conclude that a given episode of fear or concern represents a case of moral panic (Goode \& Ben-Yehuda, 2009). Armstrong wrote an article in 2007 titled Moral Panic over Meth, in which he examined the meth surge in the U.S. using the five indicators of Goode and Ben-Yehuda to measure disproportionality. Armstrong tabulated the visits to the Emergency Department and which drugs sent the most people to the Emergency Department. Disproportionality in the response to meth in Cape Town can be measured using the same framework provided 
by Armstrong. The number of articles published by The Cape Times and Cape Argus in conjunction with empirical numbers detailing the number of patients presenting with tik as the primary drug of choice can be tabulated and compared. Do a change in number of articles and their tone correspond to a change in the number of patients in treatment for methamphetamine? Moral panic rests on the case of disproportionality. In the words of Goode and Ben-Yehuda, "our knowledge of the material world is never definite, never absolutely certain and we are only permitted degrees of confidence, but for some issues that may be enough" (2009: 41). That is why the following research questions are being posed. They deal with what could be the most important indicators of moral panic.

Research Question 1: What types of words are used in The Cape Times and the Cape Argus to describe tik and tik addicts? Are these words similar to the words used in previous moral panics i.e. LSD in the 1960s, crack in the 1980s?

Research Question 2: Is there a change in number of articles and their tone and does this correspond to a change in the number of patients in treatment for methamphetamine?

The sample will be drawn by examining the LexisNexis database that publishes articles from major publications worldwide. To be included in the search articles have to discuss tik, crystal meth or methamphetamine within the context of substance abuse or use and should have been within the geographical area of the Western Cape. The time frame selected for this study is 2007 to 2012 . By noting the time frame, a correlation between research stated rate of use and addiction can be compared with the number of stories that were in the news. The data base brings up multiple publications all stories that are duplicate will be excluded. All articles having the tik in the headline will then be 
saved in and identified by a number starting from 1 . The unit of analysis is each article, the coding frame that is used is based on previous research but this will not be a restricting factor in the analyses.

The layout of this chapter will be guided by the six steps of content analysis, starting with a definition of what content analysis is and how it pertains to the current study. Followed by the sampling process and units of analysis, how the coding categories were defined, how the coding instrument came into being, including the development of the codebook, and lastly how the data were analyzed and the interpretation of the data. The purpose of this study is to utilize content analysis as a research method to explore how the tik problem was framed in the Western Cape, and to understand if the problem is an actual threat or a reflection of moral panic. Through the use of content analysis, two of the five indicators of moral panic, hostility and disproportionality, will be measured. It is generally accepted that there are six steps to content analysis:

1. Decide to use content analysis

2. Sampling

3. Units of analysis

4. Coding categories

5. Code the material

6. Analyze and interpret the results

\section{The Decision to Use Content Analysis}

The decision to use content analysis as a research method was made because content analysis is an unobtrusive technique, meaning the researcher cannot interfere with or influence the behavior of the phenomenon being studied and this can eliminate elements 
of contamination within the data. Berelson defined content analysis as a "research technique for the objective, systematic and quantitative description of the manifest content of communication" (1952:18). It involves specialized procedures for processing the scientific data. Its purpose is to "provide knowledge, new insights and a practical guide to action, by making replicable and valid inferences from data to their context" (Krippendorff, 1980: 21). The context relative to which data are analyzed must be made explicit and the aim of the inferences must be clearly stated. The main objective of content analysis is to analyze and transform information into a format that is useful and this process has four parts:

1. Summarize coded data

2. Discover patterns and relationships within the data

3. Test hypotheses about patterns and relationships

4. Relating results to other methods/situations to assess the validity

The mass media have been found to play an instrumental role in the everyday lives of people, and are generally believed to represent one of the most important influences on people's knowledge, perceptions, and behaviors (Entman, 1989). Content analysis has evolved into a scientific method which will yield inferences from verbal, symbolic or communicative data (Krippendorff, 1980). Content analysis made sense not only for the above stated reasons but also because data measures relating to tik use, distribution, and production do not present a clear picture of the problem. In line with the moral panic perspective, it was prudent to examine the media coverage of tik as the media play an important role in shaping the views of the public and policy makers. 


\section{Sampling}

Sampling is necessary if the body of material is too extensive to be analyzed in its entirety. The online newspaper archive LexisNexis was used to collate the sample of articles. Articles were drawn from The Cape Times and the Cape Argus, quality morning and afternoon papers respectively, both daily publications. These two daily publications were chosen for the current analysis as they reach a wide range of readers $(82 \%$ and $88 \%$ respectively in the Cape Peninsula), and are self-described as '...covering the latest news, in depth, with a strong local focus on current issues.' Furthermore, both are accessible online for the years of interest through the LexisNexis database. Unlike more local newspapers, The Cape Times and the Cape Argus are broadsheet papers (target audience, middle to upper class, upmarket readers) with an estimated 261,000 and 288,000 average issue readers respectively. These papers are popular in the Western Cape. There are no significant gender differences in readership (Media Club South Africa, 2013).

\section{Units of Analysis}

A search within The Cape Times and the Cape Argus for the word tik, (either in the headline or main body of the article) was performed for the six-year period January 2007- December 2012. This period was chosen as it encompasses the period just after the documented drastic rise in tik abuse, and the online database has articles from this time frame available for access. During this period there were 175 articles in The Cape Times and 317 articles in the Cape Argus. Articles were included in the sample if they met the inclusion criteria: had tik within the headline or main body and were concerned with tik use within the Geographical area of the Western Cape. Starting from January 2007, every 
second article was sampled from each newspaper. Duplicate articles were excluded from the analysis. The remaining articles published during $2007-2012$ were analyzed $(\mathrm{N}=234)$.

\section{Coding Category}

This section is an outline of the requirements that categories should meet to be included in the analyses. By adhering to these requirements the analyses is kept systematic and objective. The purpose of the coding was to explore the content of tik articles to examine how the issue was portrayed. The unit of analysis was each article on tik. The coding frame was re-evaluated after the pilot study. During the pilot stage, previous research provided a basis for coding, and enabled the coding to be updated and streamlined but this did not restrict the current analyses. New codes were allowed to emerge to ensure relevant data were not omitted. An amalgamation of both quantitative and qualitative content analysis was then conducted on the article sample to provide an overview of the portrayal of tik in the Western Cape. The main purpose of the coding frame was to ensure that the relevant data would be captured in a concise and measurable way to successfully answer the two research questions:

Research Question 1: What types of words are used in The Cape Times and the Cape Argus to describe tik and tik addicts? Are these words similar to the words used in previous moral panics, i.e. LSD in the 1960 s, crack in the 1980 s?

Research Question 2: Is there a change over time in the number of articles and their tone and does this correspond to a change in the number of patients in treatment for methamphetamine? 


\section{Code the Material}

Please see the final coding form which is included in Appendix B. The revised coding scheme included an indication of whether an article was a duplicate $(n=75)$. A duplicate article was taken to be two or more articles that were published by the same newspaper, identical in headline, word length, and content.

The next addition to the scheme was the 'words used in previous scares' these words were extrapolated from the research on previous drug scares and these words were those most commonly used to describe the drugs in the media. Substituting the word tik for meth modified three of these descriptive words (tik head, tik mouth and tik baby). The main reason for this was that, within the Western Cape crystal methamphetamine is referred to by the street name of tik. The word methamphetamine is rarely used. A simple count variable was used to capture this information by simply counting if any of these words were used within the headline or body of the article (0-23).

The next update was the inclusion of three open ended questions: tik described as; addict (main) described as; and addict (secondary) described as. These three things were included to better answer the first research question:

Research Question 1: What types of words are used in The Cape Times and the Cape Argus to describe tik and tik addicts? Are these words similar to words used in previous moral panics?

This was included to ensure the full scope of descriptive words was captured. This will also allow for a richer contextual understanding of the moral panic phenomena, by capturing any and all hyperbolic words or phrases that may indicate disproportionality or 
exaggeration, and may contribute to inciting feelings of hostility toward addicts through the use of labeling. 'Bad', 'drug of choice' and 'impairing judgment' were some of the most common descriptors used to describe tik. Other phrases included 'freely available' 'most commonly abused drug', 'a colored problem', a 'massive problem'. Perhaps the most extreme phrase was a description of tik as 'akin to apartheid'.

The coding scheme also counted if the article described criminal activity related to tik $(1=\mathrm{yes}, 0=\mathrm{no})$. This question provides more detail to the criminal activity question and also lays the foundation for the informational index that will be used to measure tone as data that could not be coded into either episodic (emotional) or thematic (logical) indices. A text box was then used to collect the relevant information. Based on the information from the pilot study, the following variables were selected to be included in this portion of the data collection sheet.

- Drug bust this was a nominal measurement of yes or no (1 or 0$)$ this differs from a drug raid in that a bust is something that has the element of surprise whereas a raid would be a planned operation carried out after careful considerations.

- Drug raid a planned operation carried to specifically recover narcotics

- Manufacturing pertaining to or mentioning the ingredients, or actual manufacturing, cooking of crystal methamphetamine or tik.

- Distribution pertaining to or alluding to the selling, or running of drugs either on a macro or micro level or having the intent to sell or distribute

- Gang related when a gang influence was mentioned or discussed this relate to involvement of gangs in the drug trade. Gang names are not relevant to the study but were noted on the side and in the SPSS data collection for later use. 
- Number of people arrested in some instances the actual number of people arrested was included in the article and this was then broken down into 4 interval groups of $5(1-5,6-10,11-15$ and $15+)$.

- Drugs seized a general list of common narcotics that came up often in the pilot study was then listed.

- Amount in Rands in some cases the police would also find hard cash or would assign a street value to the cache of narcotics confiscated. In the data collection the distinction is not important but was noted in the collection process as either hard cash or street value.

Comments or quotes, this section is important as part of the five indicators of moral panic. Knowing who is saying what about tik and addiction will provide a greater understanding of how influential the speaker is and what kind of consequences might result from these quotes. This section makes a distinction between main and secondary speakers, as some articles will use various forms of commentary to get their message across effectively.

Tone of the article is measured next by using three separate indices to categorize and identify the three themes of the article. The themes of the articles are indices that will be used to infer tone, which is one of the measures for research question two:

Research Question 2: Is there a change in number of articles and their tone and does this correspond to a change in the number of patients in treatment for methamphetamine?

This section is based on framing. Framing is defined as "the process of selecting and highlighting aspects of a perceived reality, and enhancing the salience of an 
interpretation and evaluation of that reality" (Entman, 2004:26). Or, frames can be viewed as "a central organizing idea or storyline that can shape an individual's understanding and opinion concerning an issue, by stressing specific elements of the broader controversy" (Gamson, Modigliani, 1987:143, Nelson et. al. 1997:568). Framing is based on the assumption that how an issue is characterized in the news reports can and may influence how it is understood by audiences. Early studies demonstrate the profound effect framing can have. The episodic frame utilizes more emotionally engaging words or phrases that describe concrete events or particular cases that illuminate the issue to categorize the emotional element of the article. Episodic in this instance was broken down into the emotional index by words that are descriptive and hyperbolic: 'pandemic/epidemic', 'scourge', 'abuse', 'infested'.

Thematic framing has a focus on events, usually political, and presents collective, abstract and general evidence of an issue, and was used to categorize the logical index of the article. The logical index follows the thematic frame in that, the breakdown of tik as a drug either in its chemical components, the effects and/or side effects of tik as well as how the drug is ingested. Where episodic has more human-interest detail, and tries to present a human face to the problem, thematic presents the problem in an impersonal way that does not elicit the same emotional response.

Informational as the third index, describes articles that presented evidence of tik use or abuse in a crime report style where no real human interest or emotion was present. Rather the article simply informed the public of a raid or a bust without providing a human interest angle to the story. Not every article can be said to fall wholly into a single frame and some overlap in all three or just two. Any article that had a majority of the 
components fitting into one frame was defined as representing that frame, and information representing a second frame was categorized as such.

Addiction by numbers is if the article not only mentioned that drug use was increasing or decreasing but provided a statistic to support such claims. An indication of geographical area was also taken into account, and a list of the ten most frequently cited areas was compiled from a United Nations drug report (UNODC, 2013). While this information has no direct relevance to the research questions, it is helpful in identifying problem areas and how they are described. Five of the most popular descriptions for these top affected areas were taken from the research literature, and the pilot study but new descriptors were also allowed to emerge.

Poly drug use pertains to the use of more than one substance by the addict. Research consistently highlights that most addicts make use of multiple substances. Research studies in the Western Cape highlight alcohol and Mandrax as being the most common drugs associated with addiction (Drug Wars, 2014). There was also the option of 'other' to include any other drugs that would come up and make sure that drug use could be covered completely. Research studies cited, this element was added as research shows that the inclusion of empirical data and research studies add legitimacy to articles and have also been shown to positively influence how the intended audience received the article (McNamara, n.d.17). Considering the research being studied, the last five items were included to capture if the newspapers were actually not just talking about getting help but also provided an outlet for people to start seeking help. Frequencies were run primarily to identify trends and patterns. Most of the variables are nominal and ordinal and as such appropriate statistical techniques will be applied. 


\section{CHAPTER V}

\section{DATA ANALYSIS AND DISCUSSION}

After choosing the newspapers (The Cape Times and the Cape Argus) all articles that included the word tik from these two newspapers were downloaded. With January 2007 as a starting point and ending with December 31, 2012 every story that covered tik in any manner was added to a master list. The number of articles in this master list totaled 494, with 175 articles taken from The Cape Times and 317 articles taken from the Cape Argus. This allowed the researcher to have all stories, for both newspapers during the research time frame in order to conform to the requirements of content analysis outlined previously. Once this master list was compiled, every second article for each newspaper was included in the sample. After controlling for specified dates (2007-2012) and removing duplicate articles, the total sample size for the current study was $\mathrm{N}=234$ (The Cape Times $\mathrm{n}=83$, the Cape Argus $\mathrm{n}=151$ ).

The coding instrument, based on previous literature, went through a number of changes that have been outlined in greater detail (see Chapter IV). The instrument was first applied to 39 articles during the pilot study, reevaluated and, applied to 50 articles before undergoing a final adjustment. The adjusted instrument was then used to code all 
234 articles in the sample; a copy of the final instrument together with the codebook and detailed instructions are included as appendices. The articles containing the word tik were plotted on a line graph by year to have a visual representation of articles over time.

Table 3: The Number of Articles Containing the Word Tik 2007-2012

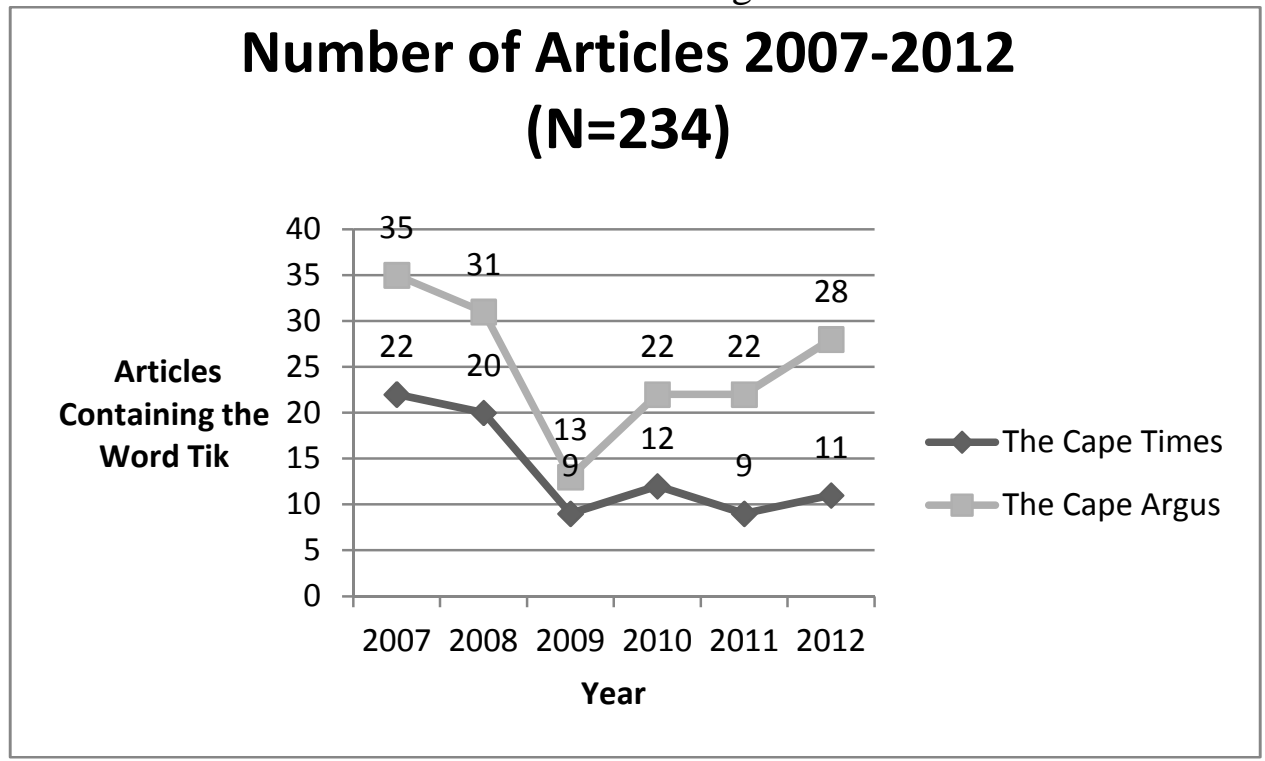

Table 3 presents a visual of the sharp decline of tik articles over the course of 2008 , and then a steady rise again in 2009 . What is of value is that both newspapers mirror the same trends, which may be attributed to the fact that they both have a strong focus on local news reporting. Another key attribute of this is that the Cape Argus accounts for $65 \%$ of all articles that report on tik in this sample, whereas The Cape Times only accounts for $35 \%$ of all articles sampled yet the reporting trend is still similar.

The first research question is conceptualized to measure the moral panic indicator of hostility. In this instance there must be an increased level of hostility toward the group or people engaging in the behavior in question. Members of this group or category are collectively designated as the enemy or an enemy, of respectable society; their behavior 
is seen as harmful or threatening to the values, the interests, possibly the very existence of the society or at least a sizable segment of that society (Goode \& Ben-Yehuda, 1994:33). This indicator also requires a clearly identifiable group to be seen as responsible for the threat and thus making a clear divide between 'us'- good, decent people and 'them'- deviants, outsiders, criminals drug users, disreputable people, (Goode \& Ben-Yehuda,1994;34). This dichotomization includes the stereotyping of these folk devils either by age, race, presumed socioeconomic status, or physical appearance.

Research Question 1: What types of words are used in The Cape Times and the Cape Argus to describe tik and tik addicts? Are these words similar to the words used in previous moral panics (e.g. LSD in the 1960s, crack in the 1980s).

The research question is then conceptualized to examine this increased hostility through a qualitative examination of the words used to describe tik and tik addicts. The behavior in question in this regard is drug addiction, specifically addiction to tik. This qualitative examination was done by allowing these descriptions to emerge through an open ended data collection approach, and then the findings were tabulated under groupings of similar themes that are in line with the moral panic framework. These themes are enmity (that appeared in $26 \%$ of these articles), synonyms of hostility or words that generate hostility, deep seated dislike or ill will, and which conjure positive feelings of hatred which may be open or concealed. The next category is threatening/ harmful and was further sub divided to delineate between the self -user- $(11 \%)$ or society (14.5\%). Stereotyping (37\%) which is a fixed generalized belief about a particular group or class of people, is usually used to convey negative impressions and can be in regard to age, race socio-economic status, physical appearance or location (Cardwell, 1996). Any 
descriptors that did not fall into these four categories were placed in the other (16\%) category. The majority of the descriptors could then be said to be stereotypes that qualitatively describe tik. 
Table 4: List of Descriptors for the Qualitative Examination of Tik

\begin{tabular}{|c|c|c|c|c|c|}
\hline $\begin{array}{l}\text { Enmity } \\
(26.4 \%)\end{array}$ & $\mathrm{n}$ & $\begin{array}{l}\text { Stereotypes } \\
(31.6 \%)\end{array}$ & $\mathrm{n}$ & $\begin{array}{l}\text { Other } \\
(16.2 \%)\end{array}$ & $\mathrm{n}$ \\
\hline bad & 2 & a cheap drug craze & 1 & banishing insecurities & 1 \\
\hline deadly & 2 & a colored problem & 1 & being mistaken for bath salts & 1 \\
\hline debilitating & 1 & a love drug & 1 & being used to sober up & 1 \\
\hline endemic & 1 & a starter drug & 1 & bigger than HIV & 2 \\
\hline epidemic & 1 & Cape Town meth capital of SA & 2 & $\begin{array}{l}\text { definite connection to the abalone } \\
\text { industry }\end{array}$ & 1 \\
\hline evil power & 1 & dominating the scene & 1 & $\begin{array}{l}\text { fueling a market for self-testing } \\
\text { drug kits }\end{array}$ & 1 \\
\hline exploded (war image) & 3 & dramatic increase & 1 & gaining popularity amongst females & 1 \\
\hline hard hitting & 1 & drug of choice & 2 & giving a sense of belonging & 1 \\
\hline most abused & 6 & easily made & 1 & hard to detect in the work place & 1 \\
\hline not an excuse for murder & 1 & enhancing sexual behavior & 1 & hype starting to fade & 1 \\
\hline rampant & 2 & escalating enormously & 3 & lessening day by day & 1 \\
\hline scourge & 2 & fastest growing drug problem in the region & 1 & mitigating factor in a murder trial & 1 \\
\hline scum & 2 & freely available & 2 & no longer drug of choice & 1 \\
\hline taken over & 1 & growing prevalence & 2 & nothing unusual & 1 \\
\hline the devil within & 1 & increasing in demand & 1 & providing a euphoric feeling & 1 \\
\hline time bomb & 1 & keeping you on a high & 1 & rapidly spreading & 1 \\
\hline $\begin{array}{l}\text { turning children into } \\
\text { monsters }\end{array}$ & 1 & like heaven & 1 & readily available & 1 \\
\hline $\begin{array}{l}\text { turning homes into war } \\
\text { zones }\end{array}$ & 1 & major problem & 6 & $\begin{array}{l}\text { surpassing that of ecstasy and } \\
\text { cocaine }\end{array}$ & 1 \\
\hline \multirow[t]{2}{*}{ worsened } & 1 & making your problems go away & 1 & & \\
\hline & & mentioned in the newspapers everyday & 1 & & \\
\hline
\end{tabular}


most commonly used drug

motivating factor behind crime

prevalent

primary or secondary substance of abuse

\begin{tabular}{|c|c|c|c|}
\hline $\begin{array}{l}\text { Harmful/Threatening to Self } \\
(11.1 \%)\end{array}$ & $\mathrm{n}$ & $\begin{array}{l}\text { Harmful/Threatening to Society } \\
(14.5 \%)\end{array}$ & $\mathrm{n}$ \\
\hline $\begin{array}{l}\text { behavioral problems similar to Fetal Alcohol } \\
\text { Syndrome (FAS) }\end{array}$ & 1 & breaks up families & 1 \\
\hline diminishes mental capacity & 2 & causes a backlog in the forensic lab & 1 \\
\hline causing psychosis & 3 & changing the nature of rapes & 1 \\
\hline impairing judgment & 1 & creating a breed of violent and aggressive rapists & 1 \\
\hline increasing risky sexual behavior & 1 & linked to premeditated murder & 1 \\
\hline inducing fury & 1 & stealing the lives of our youth & 1 \\
\hline endless stamina & 1 & highly toxic & 1 \\
\hline no fear & 1 & masking the hype of heroin & 1 \\
\hline owning your soul & 1 & capturing the soul of the youth & 1 \\
\hline \multirow[t]{6}{*}{ making him (Ashley) rob people } & 1 & akin to apartheid & 1 \\
\hline & & robbing the city of a whole generation & 1 \\
\hline & & showing no signs of letting up & 1 \\
\hline & & $\begin{array}{l}\text { sucking young girls into drug trafficking, petty crime and } \\
\text { prostitution }\end{array}$ & 1 \\
\hline & & overpowers psychiatric services & 1 \\
\hline & & destroying lives & 1 \\
\hline
\end{tabular}


devastating communities 
Tik is presented as a cheap, and freely available 'the most commonly abused drug', the 'primary substance of abuse' or 'exploding/escalating' onto the scene. The most creative description by far, is one that likens tik to apartheid. In the descriptions of tik, some reporters include the effects of the drug on the body. Aside from these, other effects include: banishing insecurities, providing a sense of belonging, enhancing sexual behavior which increases the risky sexual behavior and may exacerbate HIV/Aids levels. Violence and aggression levels are reported within some articles to increase after using tik and it is also said to cause severe behavioral problems in the scores of addicted school children.

Aside from these very correct effects, some articles also provide the indirect consequences of tik not only on the addict and their family but also the effects felt by the community. The premier of Cape Town at the time these articles were written is reported as describing tik as a 'colored problem' and while some official rehabilitation reports might be able to corroborate this statement, it is believed that a statement such as this made by a prominent political figure delineates the line between 'us' and 'them'. The set up for the folk devil can be seen in that sentence, colored people now become the generic scapegoat, and it sets the stage for hostility. Tik is also written about as 'changing the nature of rapes, creating violent offenders and leading the whole world to regarding Cape Town as being the tik capital of South Africa'. Other articles report tik as being 'difficult to detect in the work place', but it is 'destroying lives, devastating families by capturing the soul of the youth and turning these children into monsters and homes into war zones'. It is no wonder that then president Thabo Mbeki and other political figures started to follow in the footsteps of the United States and openly 'declared war on tik'. 
Table 5: Qualitative Descriptors of Tik Addicts

\begin{tabular}{|c|c|c|c|}
\hline $\begin{array}{l}\text { Descriptors of Main Addict } \\
(69 \%)\end{array}$ & $\mathrm{n}$ & $\begin{array}{l}\text { Descriptors of Other Addicts } \\
(31 \%)\end{array}$ & $\mathrm{n}$ \\
\hline a real headache & 1 & alert & 1 \\
\hline a well-known drug dealer & 1 & colored & 2 \\
\hline altered state of consciousness & 1 & forlorn & 1 \\
\hline authority on drug use & 1 & gaunt & 2 \\
\hline baby on her hip & 2 & $\begin{array}{l}\text { holding up pants even with a } \\
\text { belt }\end{array}$ & 1 \\
\hline barbarians & 1 & & \\
\hline clones & 1 & predominantly male & 1 \\
\hline committing violent and sick crimes & 1 & single & 1 \\
\hline convicted rapists & 1 & staying awake for days & 1 \\
\hline coping with the pressures of modern society & 1 & sunken skin & 2 \\
\hline creatures of habit & 1 & & \\
\hline danger to the community & 1 & their minds gone & 1 \\
\hline desperate to get off the streets & 1 & tik generation & 1 \\
\hline displaying evidence of a mental disturbance & 1 & toothless smile & 1 \\
\hline drug crazed & 1 & unemployed & 1 \\
\hline drug fuelled super moms & 1 & walking skeletons & 1 \\
\hline flight risk & 1 & young old face & 1 \\
\hline forlorn & 1 & & \\
\hline former addict and dealer & 1 & & \\
\hline grant money to support her habit & 2 & & \\
\hline hitting rock bottom & 1 & & \\
\hline
\end{tabular}


losing their power of choice

murdering himself through drugs

nonchalant

senior provincial director of social welfare stealing to support her habit

stigmatized addict

stopping at nothing for cash to get tik

tik fuelled

tik monster

unashamed addict

walking sexual risk time bombs

zombies

1 
This is how tik was reported in the newspapers. Addicts were mainly referred to as 'drugfuelled tik monsters' who are 'mainly colored' and who come across as 'forlorn zombies'.

To answer the second part of the research question, each coding instrument had a list of words used in previous scares. This was to keep track of how many words could be transposed from previous scares and would also help indicate if there were elements of a moral panic at hand. Below is the table of words $(n=23)$ that have been found in other research dealing with moral panic 
Table 6: Previous Scares Frequency Chart $(n=63)$

\begin{tabular}{|c|c|c|}
\hline Word & $\mathrm{n}$ & $\%$ \\
\hline cheaper than cocaine & 5 & 21.7 \\
\hline crime generating & 2 & 8.6 \\
\hline crisis & 9 & 39.1 \\
\hline dangerous & 4 & 17.3 \\
\hline demon drug & 1 & 4.3 \\
\hline infested & 0 & 0 \\
\hline instant addiction & 0 & 0 \\
\hline new drug of choice & 18 & 78 \\
\hline pervasive & 1 & 4.3 \\
\hline plague & 0 & 0 \\
\hline ravage & 3 & 13 \\
\hline scourge & 23 & 100 \\
\hline sweeping the country & 3 & 13 \\
\hline terrifying & 0 & 0 \\
\hline threatening & 4 & 17.3 \\
\hline $\begin{array}{l}\text { tidal wave (substance } \\
\text { abuse) }\end{array}$ & 0 & 0 \\
\hline tik baby & 4 & 17.3 \\
\hline tik head & 2 & 8.6 \\
\hline tik mouth & 0 & 0 \\
\hline universal & 3 & 13 \\
\hline unprecedented & 1 & 4.3 \\
\hline wave & 0 & 0 \\
\hline widespread & 3 & 13 \\
\hline
\end{tabular}

Of the entire sample ( $\mathrm{N}=234)$, only 63 articles had any one or more of the above words in the write up. Fifty articles had 1 word, 12 articles had 2 words, 3 articles had 3 and only 1 article had 4 words $(n=63)$. The words were counted as being direct, either from the headline or the main body. The chart below shows the eight words that were the most frequent and that are alike from previous research on moral panic. 
Table7: The Most Common Words from Previous Scares Found in this Study

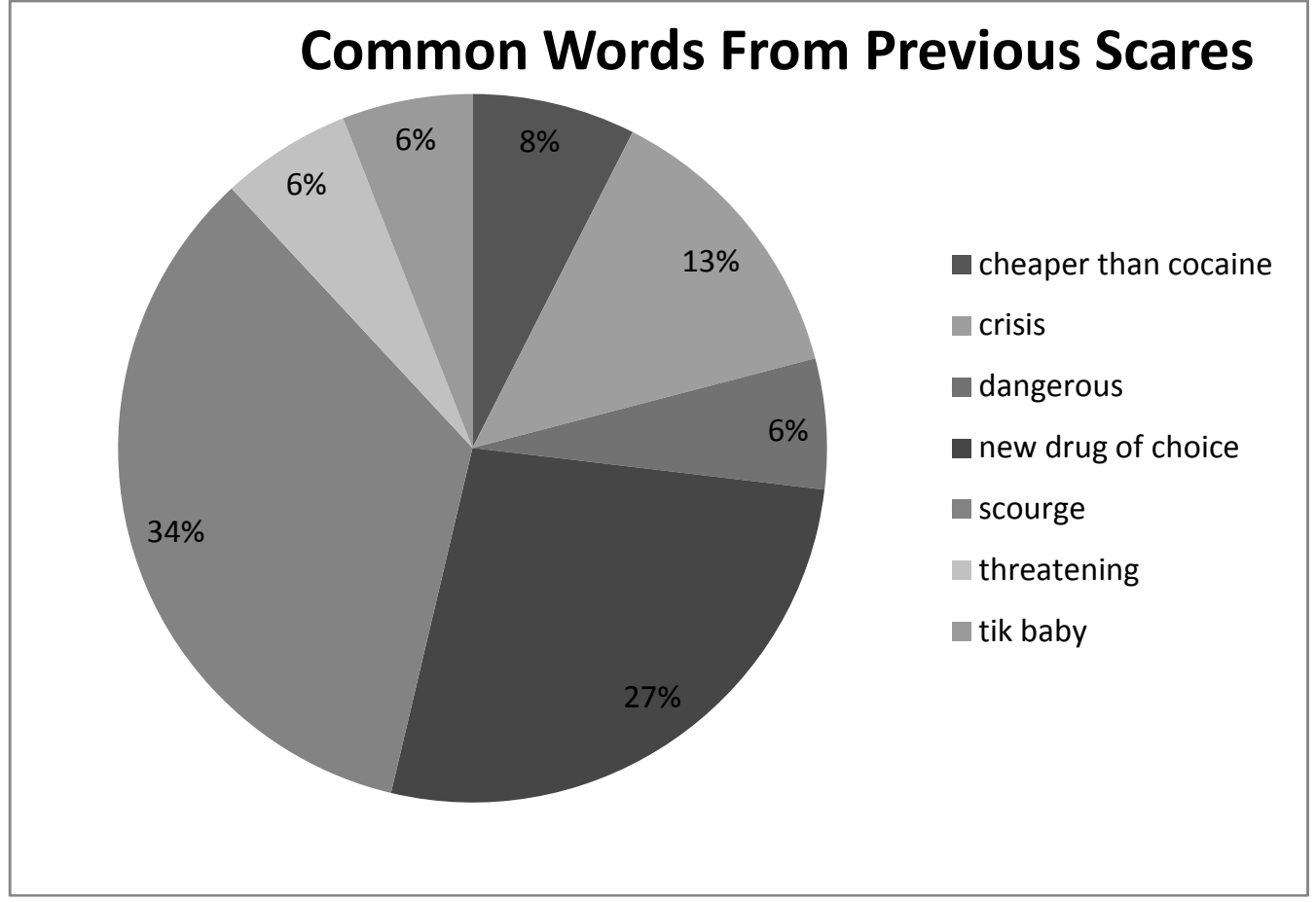

\section{Discussion Research Question One}

The first research question was designed to measure the element of hostility as one of the five indicators of moral panic. Goode and Ben-Yehuda write that during an instance of moral panic these levels of hostility toward the deviant group or folk devil will be increased. Not only are members of the deviant group collectively designated as the enemy of respectable society but their behavior is seen as harmful or threatening to the values of society (2009). At this stage of moral panic, an identifiable group must be seen as responsible for the condition, phenomenon or behavior and this group is then stereotyped and the hostility can be expressed in the stereotyping of this responsible deviant group. In the Western Cape research first identified this group as being predominantly male, late 20's and colored (Pludderman, et al., 2010). The premier of 
Cape Town at the time Rassol Ebrahim openly admitted to calling tik a 'colored problem'. Where research established a responsible group, a moral entrepreneur effectively identified and put a group up to be stereotyped and gave a face to the tik problem which sets up the conditions for hostility to blossom. Cohen (2002) identified politicians and law makers as 'moral entrepreneurs' and when they take the stand and openly declare war on tik, they establish the 'good' and 'bad', the scapegoat or folk devil against whom good citizens must stand up. Media articles single out threats, generate alarm and direct attention to these folk devils and this is seen as the "chief function of the media" (Goode \& Ben-Yehuda, 2009:90-91). When the media expresses fear or concern about a threat or supposed threat that in and of itself constitutes a measure of moral panic. Cohen in Folk Devils and Moral Panics (1972:2002) also lists melodramatic vocabulary as one of the forms of media exaggeration.

Scourge is defined by the Merriam-Webster Dictionary as 'something that causes great trouble or suffering', and it is rather fitting that that word is the most common word used to describe the tik issue in the Western Cape and also in previous drug scares. While 16 of the 23 words used in previous moral panics were found in these newspaper articles, and while some articles make a clear divide between "us" and "them" $(n=63)$, this is not enough evidence to support the indicator of hostility.

Would $27 \%$ of the articles reporting in a manner consistent with what could be considered exaggeration be enough to rule that the criteria of hostility are met? It may be more prudent to say that while the criteria of hostility have been met they have not been met at a level that many would consider significant. These select few $(n=63)$ articles if they had to be judged on their own would be in line with Cohen's rhetoric as they display 
exaggeration. The moral entrepreneurs are quoted as championing their causes and tik is presented as the enemy that is tarnishing the good name of Cape Town. In the grand scheme of it, most of the reporting does not incite hostility ( $n=234)$. Only $27 \%$ of the articles sampled could be said to incite hostility and while the moral entrepreneurs quoted may have legitimacy and standing in the community, statistically there is no evidence of hostility as a component of moral panic in the majority of sampled articles from The Cape Times and the Cape Argus. Rather, the articles cover more informational aspects of tik, such as informing the society of major arrests, raids and about the success of community led initiatives. This provides a transition into the second indicator that will be measured: disproportionality.

The purpose of the research question is to determine if the trend in reporting from both The Cape Times and the Cape Argus matched the trend in people seeking treatment for tik abuse. The tone of the article for this study refers to the way in which the sampled articles were framed.

Research Question 2: Is there a change in number of articles and their tone and does this correspond to a change in the number of patients in treatment for methamphetamine?

This question can be broken down into three components $a$ ) change in the number of articles, $b$ ) the article tone and $c$ ) do these changes correspond to the number of patients in treatment for tik.

In line with the moral panic perspective the coverage of tik was examined again by the number of articles per year. The amount of coverage that tik received between 2007 and 2012 would suggest if the media was alluding to a tik problem when none was 
evident. Table 1 in the literature review, presented the tik abuse statistic by percentage and year while Table 2, presented the number of patients by year. Comparing findings with the results of the data collected in this study, it would appear that 2007 and 2009 are important as these years represent an increase in tik abuse (2007 a, 41\%, 2007 b.36\%, $2009 a, 41 \%$ and $2009 b, 35 \%$ ) but the number of articles declines sharply in 2009. So while 2007 may be adequately represented in the coverage of tik, 2009 is not when comparing the tik abuse rate with number of articles. An increase in patients in treatment (2005, 952 patients to $2007 a, 1413 ; 2007 b$, respectively) is also not represented well in terms of newspaper coverage by The Cape Times and the Cape Argus. In 2012 there was an average of 1189 patients in 23 specialist treatment Centre's in Cape Town and only 37 articles were noted that mentioned tik.

The analysis consisted of 224 articles that were coded for tone. Tone in the context of this study refers to the specific frame of each article that was divided into three separate indices: 1) emotional, 2) logical and 3) informational. According to Agenda Setting Theory the way in which an article is framed will not only influence what the public thinks, but also how the public thinks. First developed in 1972 by McCombs and Shaw to examine "how the media set the agenda for each political campaign" (McCombs \& Shaw, 1972:177) the basic foundation of this theory is that people will determine what issues are important based on the media coverage (Lang \& Lang, 1991). The second level of this theory hypothesizes that the public is influenced by the way the media frames the issue, and framing can also be utilized as an analytical tool that is inductive in nature.

The focus of the study at this point was to identify and describe both implicit and explicit ideas and themes within the data. Codes were then developed to represent the 
three identified indices (themes). This thematic analysis is therefore geared toward capturing the complexity of meaning within a textual data set. In this study two of the three distinct frames are based on episodic and thematic framing, and constitute two intellectually distinct appraisal contexts that should be expected to generate different emotional reactions.

The episodic frame was used to index the category emotional; the purpose of this index was to capture the words that would illicit an emotional response from the readers. The purpose of episodic framing is to put human interest detail into a more event orientated report that will depict public issues in a more concrete instance with little or no context about the actual issue. Episodic framing is also seen in articles that feature highly descriptive and figurative language, as such language creates more sensationalized news frames that are able to detract from the important information and draw attention to isolated events that in this instance would place tik out of context (Blood, 2002).

The thematic frame was used to categorize the logical index, because thematic framing places issues in a broader more general context with the inclusion of statistics, or expert analysis, words or phrases that listed the ingredients, effects or known side effects of tik was placed in this index as these were considered to be broad issues that are generally associated with tik. Thematic framing can also present abstract information, policy problems all in an impersonal account that does not provide specific characters at which the readers may direct an emotional reaction.

The last index category was informational; the purpose of this index was to capture information that could not be coded as either emotional or logical. This index was 
relegated to capturing information pertaining to criminal activity, reported crime and matter of fact information such as police reports informing the community of drug related crimes, and in some instanced highlights and follow ups of cases brought before the magistrates at the court house in Cape Town.

The initial article sample was 234 articles from The Cape Argus and the Cape Times, for this section of analysis a tally captured the count of how many words or phrases were in each index (Count_Emo, Count_log and Count_Info), then each word or phrase was listed as a separate variable $(1=$ yes and $0=$ no). After coding the variables for each of the three indices a final count would place one index as having the highest count of variables and this was how a theme was established. In the few instances where there was sufficient information to view an article as overlapping into another frame, a sub theme code was allocated to take this into account. 10 articles did not meet the criteria to be coded into any index resulting in the analyses for Research Question 2 using a sample of 224 articles to indicate and generate a theme, which would then be used to infer tone. 
Table 8: Article Tone over Time

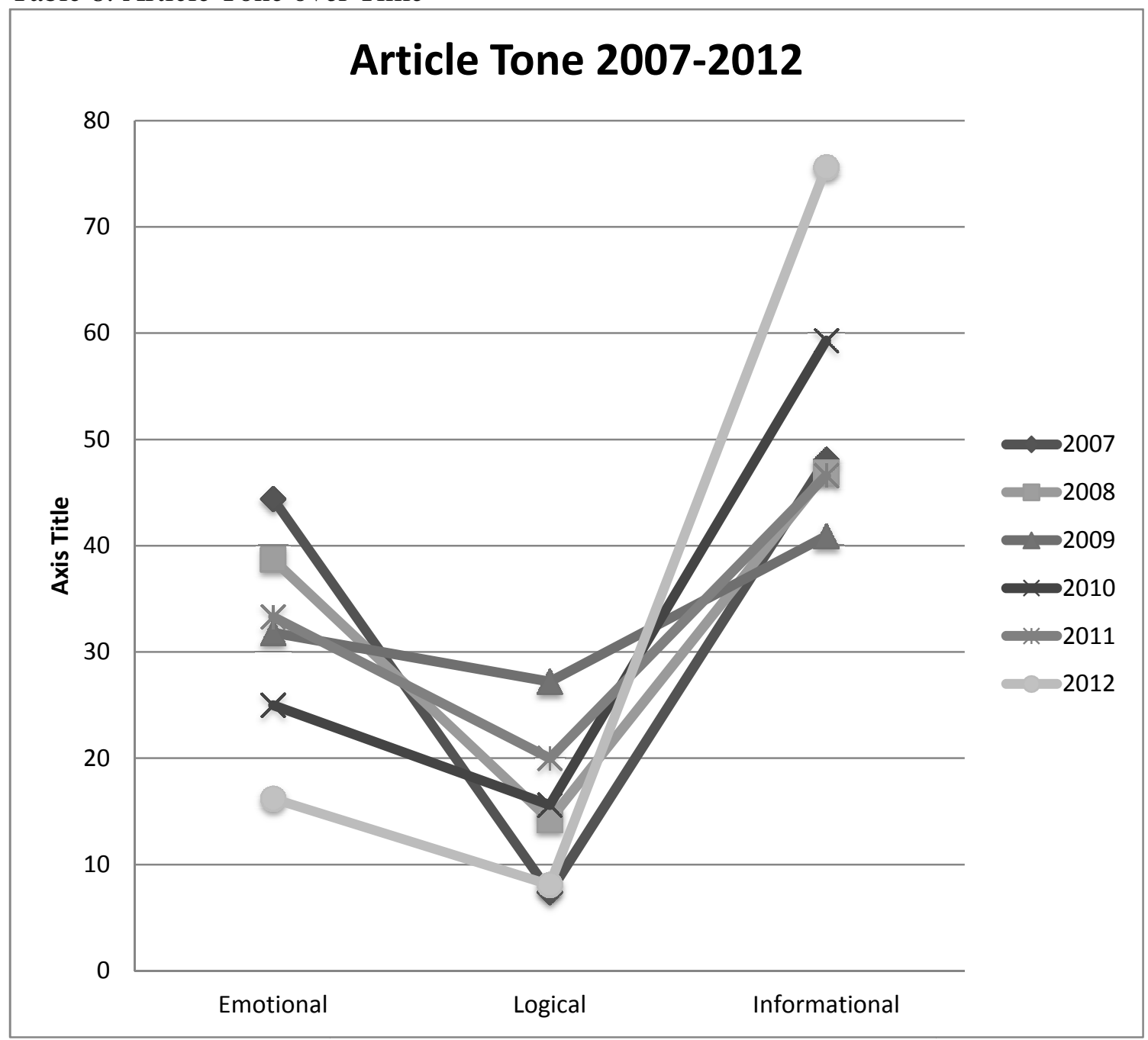

Table 8 shows the trends of article tone over the six year period 2007-2012, in percent. It is interesting to note that each index was rather steady throughout the years. The year 2007 had the most articles coded for tone $(n=54)$, this number dropped in 2008 $(n=49)$, but in the entire six year period $2009(n=22)$ had the lowest count. To examine the trend against the number of patients seeking treatment, data were obtained from the South African Community Epidemiology Network on Drug Use (SACENDU) that monitors alcohol and drug abuse treatment admissions in South Africa. These data are available from a number of phases, and by comparing data from phase 32 (2013), that 
documents the number of patients from 23 specialist Centre's on a monthly basis in Cape Town, one is able to graph the trend of articles, their tone and number of patients over the study time frame 2007-2012.

Table 9: Article Tone, Patients in Treatment Trends 2007-2012

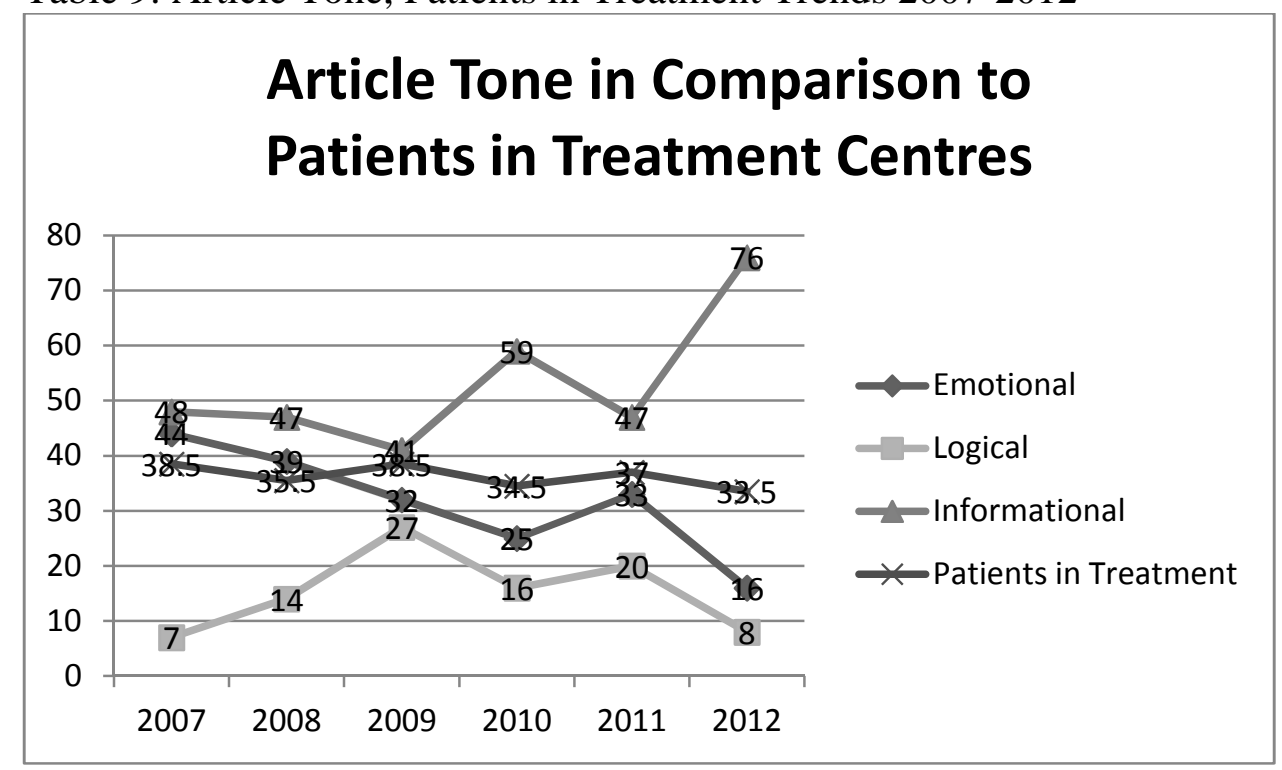

These results make sense if one views the matter of drug addiction as a sort of delayed reaction, meaning the consequences of tik would not be felt immediately. Consider that the drug is seen to have peaked in 2006, yet the highest article count is in 2007. Next consider that 2008 on average had the least amount of recorded patients $(n=965)$ and then 2009 had the least amount of article coverage $(n=22)$. This pattern can be observed by looking at the number of patients for the given year and then checking that against the number of articles printed for the following year. For example, in 2009 there was an increase in patients and a subsequent increase in the number of articles printed in 2010. Observing this phenomenon in real time one could say there is no disproportion and that the issue is not being exaggerated as the trend does mirror both the logical and emotional tone. After consideration, this question does not address 
exaggerated figures, the empirical data do suggest that tik is still the number one substance that addicts present with when seeking help even ahead of alcohol and heroin at these places of treatment. Thus, the criterion of disproportion is not met.

By definition atrocity stories could be said to fall under the episodic frame, and the results show that informational far exceeds emotional, the criterion of disproportion is therefore not met. Subsequently considering that the content analysis was not comparing tik to other narcotics a comparison is not available to determine if there is greater attention paid to the issue of tik as opposed to another drug or vice one cannot with certainty say that the criterion of disproportion is met in this instance. Because the rate of use of tik is shown to have remained fairly steady over this six year period, and taking into account the lag in reporting notion one cannot conclude the criterion of disproportion was met.

\section{Discussion Research Question Two}

In their narrative of Moral Panics: The Social Construction of Deviance, Goode and Ben-Yehuda (2009:44-46) went into more detail for the fourth indicator of moral panic disproportion, by providing five sub indicators that may be used to solidify the main indicator of disproportion. First, where any figures that are cited to measure the scope of the problem are grossly exaggerated one may say the criterion of disproportion has been met. Second, if the concrete threat that is feared is by all available evidence, nonexistent, one may say the criterion of disproportion has been met. Third, if atrocity stories are told and believed about nonexistent harm, one can say the criterion of disproportion has been met. Fourth, if the attention paid to a specific condition is vastly 
greater than that paid to another condition, and the concrete threat or damage caused by the first is no greater than or is less than the second one can say the criterion of disproportion has been met. Fifth, if the attention paid to a given condition at one point in time is vastly greater than that paid to it during a previous or later time, without any corresponding increase in objective seriousness then once again, one may say the criteria of disproportion has been met. The findings from research question two do not meet the sub indicators of disproportion, thus the criterion of disproportion has not been met.

Observing the frames used to report on this drug, informational came out ahead even after that rather deep dive between 2009 and 2011 to surge up past its 2007 high in 2012. This suggests that the news reporting focused on the facts and not on exaggerating, making claims or causing panic. The indices that were conceptualized to account for and infer tone were important for the indicator of disproportion because exaggeration was a key factor in previous moral panics (Cohen, 2002). To reiterate, the way in which an issue is framed will influence not only what they think of an issue but also how they think of that issue. While logical, came in last with the least amount of each year shows that framing tik in relation to side effects was not a popular choice. The articles were overwhelmingly informational, indicating that the crime and criminal element was more important when it came to the reporting of this issue. The very concept of moral panic is said to rest on disproportion, and the notion at this stage that disproportion has not been met means quite simply that there is no evidence of a moral panic over tik in the Western Cape. 


\section{CHAPTER VI}

\section{RECOMMENDATIONS AND CONCLUSION}

\section{Practical Recommendations}

My research had a number of limitations, which can be used as the basis for recommendations. This research could be said to be limited as I was the only one responsible for drawing up the coding frame, conducting the pilot study, and then the final data collection that resulted in this product. This research, being part qualitative, is limited in terms of generalizability as only the Western Cape was examined. Further the research time frame began in 2007 during the physical peak of tik use. Content analysis as a research method is generally conducted when one or more researchers will draft the study and employ trained coders to collect the relevant data; in this case this was not an option available to me. Analyzing written material systematically through content analysis is about extracting insights from already existing data sources. This is a great tool to analyze large amounts of data, provided there are explicit coding instructions, precise categories and together with extensive reliability checks and trained individuals to code the material. A major downside to content analysis, besides it being costly in some 
instances, is time constraints. In spite of these shortcomings the research does provide important conclusions.

\section{Conclusion}

The purpose of this study was to explore the perceptions of tik in the Western Cape of South Africa, through an examination of The Cape Times and the Cape Argus within the framework of moral panic to understand if tik is an actual threat or a reflection of moral panic. Two research questions were posed to measure two of the five indicators of moral panic-Hostility and Disproportionality. In the theoretical framework outlined previously, some assumptions were made; one was that the Western Cape was in the midst of a moral panic surrounding tik. The second assumption was that tik was moving up to join alcohol on its infamous pedestal. The last assumption was that tik had the potential to become an undesirable part of the culture. It was found that the Western Cape was not in the midst of a moral panic. Tik has, according to SACENDU, for a number of years now knocked alcohol off its pedestal. As for it becoming an undesirable part of the culture that is one aspect that can be addressed in future research.

Future studies should examine these research questions using non prominent newspapers to compare the reporting style, and even across the other eight provinces to examine whether others provinces may be inciting moral panic away from the locus of the problem. Another area of research might expand the search criteria to include all drugs in the list to see how different drugs are reported, and if the tone changes with different drugs. A greater depth of information may have been obtained by measuring all five indicators of moral panic as this could have added greater insight into the perceptions 
surrounding tik on a national level. Another possible improvement may have been sampling from two newspapers per province, but time was a constraint in both regards. Another aspect for future research may be the inclusion of interviews with key individuals that Cohen (2002) would label moral entrepreneurs as other studies have done and which would enhance the criteria of hostility through the use of framing. Research in agenda setting highlights that not only does the media influence to some degree what we think, but also how we think and the status of the person issuing statements in the media carries some weight in this media influence.

This thesis outlines the literature leading up to the formalization of moral panic, the indicators used to examine moral panic and how it can be applied to a social issue, in this case tik. Two of the five indicators were then applied to the Western Cape of South Africa, to examine if there was a moral panic surrounding tik or if it was an actual threat. The finding of this study suggests that tik is an actual threat and that the Western Cape is not in the midst of a moral panic surrounding tik. 


\section{REFERENCES}

Armstrong, E. G. (2007). Moral Panic over Meth. Contempory Justice Review, 427-442.

Barak, G. (1994). Media, Process and the Social Contruction of Crime. New York: Garland.

Becker, H. (1963). Outsiders: Studies in the Sociology of Deviance. New York: The Free Press.

Beckett, K. (1994). Setting the public agenda: Street crime and drug use in American politics. Social Problems, 425-447.

Behr, M. (2006, August). Tik...Tik...Boom! FHM.

Bennett, W., Diilulio, J., \& Waters, J. (1996). Body count: Moral poverty and how to win America's war against crime and drugs. New York: Simon and Schuster.

Berelson, B. (1952). Content analysis in communication research. New York: The Free Press.

Blood, R. W., Putnis, P., \& Pirkins, J. (2002). Mental-illness news as violence: A news frame analysis of reporting and portrayal of mental health and illness in Australia media. Australian Journal of Communication, 59-82.

Blood, R. W., William, J., \& McCallum, K. (2003). Representations of public risk: Illegal drugs in the Australian press. Media International Australia Incorporating Culture and Policy, 82-100.

Brand South Africa. (2013, September 06). Media Club South Africa. Johanesburg, Gauteng, South Africa. Retrieved from www.mediaclubsouthafrica.com/images/stories/june2009/newspapers.jpg\&descri ption=The press in south africa

Brecher, E. M. (1972). Licit and Illicit Drugs. Boston: Little, Brown.

Bridgland, F. (2013, November 17). South Africa Breaks Bad. Herald Scotland, p. 1.

Burns, R., \& Crawford, C. (1999). School Shootings, the Media and Public Fear: Ingredients for a Moral Panic. Crime, Law and Social Change, 147-168 
Caputo, A. (2013). Cultural Models Shaping Stalking from a Content Analysis of Italian Newspapers. Europe's Journal of Psychology, 443-460.

Chass, M. (2002, May 31). On Baseball. The New York Times, p. D4.

Cohen, S. (1972). Folk Devils and Moral Panics. Oxford: Martin Robertson.

Cohen, S. (1973). Folk Devils and Moral Panics: the creation of the Mods and Rockers. St Albans: Paladin.

Cohen, S. (1980). Folk Devils and Moral Panics: the creation of the Mods and Rockers. London: MacGibbon \& Kee Ltd.

Cohen, S. (2002). Folk Devils and Moral Panics. London and New York: Routledge.

Cohen, S. (2002). Folk Devils and Moral Panics: The Creation of Mods and Rockers. Oxford, UK: Routledge.

Cornwell, B., \& Linders, A. (2002). The myth of 'Moral Panic' an alternative account of the LSD prohibition. Deviant Behaviour, 307-330.

Courtwright, D. T. (2001). Forces of Habit. Cambridge, MA: Harvard University Press.

Critcher, C. (2003). Moral Panics and the Media. Buckingham, Philadelphia: Open University Press.

Daley, S. (1999, July 9). Workers' Free Wine Ends, but South Africans still pay. The New York Times, p. 1.

Entman, R. (1989). How the Media Affect What People Think: An information processing approach. The Journal of Politics, 347-370.

Entman, R. (2004). Projections of Power: Framing News, Public Opinion and U.S. Foreign Policy. USA: The University of Chicago Press.

Franschhoek Life Magazine. (20007, February). The Devils drug: Tik. Franschhoek Life Magazine, pp. 20-32.

Furendi, F. (1994). A Plague of Moral Panics. Living Marxism.

Furendi, F. (2005). Politics of Fear. Continuum Press.

Gamson, W. A., \& Modigliani, A. (1987). The changing culture of affirmitive action. In R. G. Braungart, \& M. M. Braungart (Eds.), Research in Political Sociology (pp. 137-177). Greenwhich,CT: JAI Press.

Goode, E. (2008). Moral Panics and Disproportionality: the case of LSD use in the sixties. Deviant Behaviour, 533-543. 
Goode, E., \& Ben-Yehuda, N. (1994). Moral Panics: the social contruction of deviance. Cambridge: Blackwell.

Goode, E., \& Ben-Yehuda, N. (2009). Moral Panics: The Social Construction of Deviance. Wiley-Blackwell.

Hall, S., Critcher, C., Jefferson, T., Clarke, J., \& Roberts , B. (1978). Policing the Crisis: Mugging, the State and Law and Order. New York: Holmes and Meiser.

Humanitarion News and Analysis. (2009). South Africa: Coming to terms with the tot system's hangover. Cape Town: IRIN News.org.

Hunt, A. (1997). 'Moral Panic' and moral language in the media. British Journal of Sociology, 629-647.

Jamieson, K., \& Campbell, K. (2006). The Inteplay of Influence. Belmont, CA: Wadsworth.

Jenkins, P. (1999). Synthetic Panics: The Symbolic Politics of Designer Drugs. New York: New York University Press.

Jenkins, P. (2009). Failure to Launch: Why do some social issues fail to detonate moral panic? British Journal of Criminology, 35-47.

Kids as young as nine addicts. (2011, July 21). The Cape Argus, p. 3. Retrieved from www.lexisnexis.com

Krippendorff, K. (1980). Content Analysis: An introduction to its methodology. Beverly Hills, London: Sage Publications.

Lasswell, H., Lerner, D., \& Pool, I. d. (1952). The comparitive study of symbol: an introduction. Stanford: Stanford Univerity Press.

Leggett, T. (2003). On the Tuk Tuk Express: Has Methamphetamine hit the Cape Flats. SA Crime Quarterly, 33-35.

Lewis, E. (2009, February 10). "God wants me to talk" Pakkies; tik addict mom tells residents of her ordeal. The Cape Argus, p. 9. Retrieved from www.lexisnexis.com

Linnemann, T. (2010). Mad Men, Meth Moms, Moral Panic: Gendering Meth Crimes in the Midwest . Critical Criminology, 95-110.

Macnamara, J. (2005). Media content analysis: Its uses, benefits and best practice methodology. Asia Pacific Public Relations Journal, 1-34.

Manderson, D. (2005). Possessed: Drug Policy, Witchcraft and Belief. 19 Cultural Studies, 36-63.

Media Club South Africa. (2013, September 6). Brand South Africa. Retrieved from Media Club South Africa: www.mediaclubsouthafrica/newspapers.htm 
Myers, B., \& Parry, C. D. (2003). Fact Sheet- Substance use by South African adolescents. ALcohol and Drug Abuse Research Group, Medical Research Council. Retrieved from SA Health:

http://www.sahealthinfo.org/admodule/substance.htm

Nelson, T. E., Clawson, R. A., \& Oxley, Z. M. (1997). Media Framing of a Civil Liberties COnflict and its Effect on Tolerance. American Political Science Review, 567-583.

Neuendorf, K. A. (2002). The Content Analysis Guidebook. Sage Publications.

Nichols, C. (2013, October 28). Tik Declared New Drug of Choice in South Africa's Cape Town. Recovery Now Newspaper, pp. 1-2.

Nyabadza, F., \& Hove-Musekwa, S. D. (2010, November 19). Substance abuse in the Western Cape Province of South Africa: Insights through Mathematical Modelling. SACEMA Quarterly, pp. 1-3.

Nyabadza, F., Njagarah, J. B., \& Smith, R. J. (2012). Modelling the Dynamics of Crystal Meth ('Tik') Abuse in the Presence of Drug Supply Chains in South Africa. Society for Mathematical Biology, 1-12.

Oksanen, A. (2013). Deleuze and the Theory of Addiction. Journal of Psychoactive Drugs, 57-67.

Parry, C. D., Myers, B., \& Pludderman, A. (2004). Drug Policy for Methamphetamine Use Urgently Needed. South African Medical Journal.

Peltzer, K., Ramlagan, S., Johnson, B. D., \& Phaswana-Mafuya, N. (2010). Illicit Drug Use and Treatment in South Africa: A Review. Substance Use and Misuse, 22212243.

Pludderman, A., Dada, S., Parry, C., Bhana, A., Bachoo, S., Perreira, T., . . Freytag, K. (2010). Monitoring alcohol and drug abuse trends in South Africa (July 1996June 2010). SACENDU Research Breif.

Pludderman, A., Hone, S., Bhana, A., SANCA, Potgieter, H., Gerber, W., . . Parry , C. (2007). Monitoring Alcohol and Drug Abuse Treatment Admissions in South Africa. Tygerberg: South African Community Epidemiology Network on Drug Use.

Pludderman, A., Parry, C. D., Bhana, A., Harker, N., Potgeiter, H., Gerber, W., \& Johnson, C. (2005). The South African Community Epidemiology Network on Drug Use (SACENDU): Monitoring Alcohol and Drug Trends in South Africa. Research Briefs (July 1996-December 2004).

Powell, A. (2007, July 24). The Cape Times. Retrieved from www.lexisnexis.com

Reinarman, C., \& Levine, H. (1989). Crack in context: Politics and media in the making of a drug scare. Contempory Drug Problems, 535-577. 
Reinarman, C., \& Levine, H. (1997). Crack in AMerica: Demon Drugs and Social Justice. Los Angeles: University of California Press.

Rohloff, A. (2011). SHifting the Focus? Moral Panics as Civilizing and Decivilizing Processes. In S. P. Hier (Ed.), Moral Panics and the Politics of Anxiety (pp. 7185). London: Routledge.

Samodien, L. (2008, December 3). Ellen Pakkies was 'desperate'. Cape Argus.

Sheff, D. (2005, February 6). My addicted son. The New York Times Magazine, pp. 4247.

Sindell, R. (1990). Street Violence in the Nineteenth Century: Media Panic or Real Danger? Leicester: Leicester University Press.

South Africa History Online. (2013, September 6). Apartheid and its Legacy. Retrieved from SA Histrory online: www.sahistoryonline/aparheid/dop-system-capetown.htm

SouthAfricanInfo. (n.d.). Retrieved from www.southafricainfo.co.za

UNODC. (2013). World Drug Report. Vienna: United Nations .

van Teijlingen, E., \& Hundley, V. (2001). The importance of pilot studies. Social Research Update, 1-3.

Wechsberg, W. M., Luseno, W. K., Karg, R. S., Young, S., Rodman, N., Myers, B., \& Parry, C. D. (n.d.). Alcohol, Cannabis and Meth use and other Risk Behaviour among Black and Colored South African Women: A small randomized trial.

Weisheit, R. A., \& Wells, E. (2010). Methamphetamine Laboritories: The Geography of Drug Production. Western Criminolgy Review, 11(2), 9-26.

Weisheit, R., \& White, W. L. (2009). Methamphetamine: its history, pharmocology and treatment. Center City, Minnesota: Hazelden.

Welch, M., Price, E. A., \& Yankey, N. (2002). Moral panic over youth violence. Youth \& Society, 3-30.

Young, J. (2009). Moral Panic: Its Origins in Resistance, Ressentiment and the Translation of Fantasy into Reality. British Journal of Criminology, 4-16.

Zapata, L. B., Hillis, S. D., Marchbanks, P. A., Curtis, K. M., \& Lowry, R. (2008). Methamphetamine Use is Idependantly Associated with Recent Risky Sexual behaviours and Adolescent Pregnancy. Journal of School Health, 641-648. 
APPENDIX A

PILOT STUDY, CODE BOOK AND COLLECTION SHEET 


\section{Pilot Study}

Before reaching this stage of research, a short pilot study or test run was done. This was considered to be a crucial element, as pilot designs are used to develop and test the adequacy of the research instrument as well as establishing whether the sampling frame and technique are effective, and if the study is worth completing on a full scale (van Teijlingen and Hundley, 2001:1). The sample for the pilot study was drawn by examining the media that publishes in the Western Cape. According to Media Club South Africa there are 23 daily and 14 weekly major urban dailies (Media Club South Africa, 2013). As a country there has always been an opinionated and strong press presence and even through the harsh legislation of apartheid the press reported all they could. They still report on all they can under freedom of the press in the democracy. The newspapers were selected based on those that published stories in the Western Cape and those that had an online presence. South Africa has 11 official languages, and for ease of reading only English newspapers, available online, and pertaining to the Western Cape was selected. The newspapers were processed through the IOL database; IOL is an independently owned and run publication company that publishes a number of newspapers, The Cape Times, the Cape Argus, Daily Voice and many others. The West Cape News is published under a different publishing house.

To be included in the search articles must have the key words, tik, crystal meth or methamphetamine within the context of substance abuse or use and within the geographical area of the Western Cape. For this pilot study, the articles sampled were from 2005-2013. 
By noting the time frame, a correlation between research stated rate of use and addiction can be compared with the number of stories that were in the news. Since the data base brings up multiple publications all stories that are duplicate were excluded.

For the pilot study, a general start to data collection came by accessing the IOL website and entering tik as the main key word; all articles having the tik in the headline were then saved in and identified by a number starting from 1 . The unit of analysis is each article, the coding frame that is used is based on previous research but this was not a restricting factor in the analyses. New codes will be allowed to emerge in this part of the study to ensure that all relevant data are not omitted in future collection efforts.

Articles were also coded for presence (1) or absence (0) of treatment facilities and contact information as well as demographic information pertaining to the main user and other user that may have been mentioned. The actual reference to geographical area (1) or lack thereof (0) and how it was described within the article were also coded for a description of tik, how it is ingested and the effects of the drug. For example, articles that used descriptive adjective such as abuse, pandemic/epidemic versus a more scientific or logical approach of risky behavior, risk of HIV/AIDS. The data was then entered into SPSS and analyzed. Article characteristics were noted, including the number of words, and date and year of publications. Each article was coded for tone, personable/emotive, scientific/logical or neutral. A full codebook and data collection sheet has been included in this appendix at the end for reference.

After conducting this pilot study some flaws were discovered in the theoretical framework, as well as in the sampling frame and data collection instrument. The pilot 
study utilized too many theoretical aspects that made it difficult to pinpoint an exact point of reference and added to clutter within the data collection instrument. For the pilot study, LexisNexis was not used as the main database, rather the direct IOL website that publishers both The Cape Times and Cape Argus were used. This lead to insufficient articles $(\mathrm{N}=34)$ and a problem with coding as the IOL database included other publications not only the two that were referenced as being used. The research questions within the pilot study were to a point rendered null as there was not sufficient information to be coded from the articles to actually answer the questions. As a result, the pilot study was instrumental in streamlining the process. 


\section{Codebook Pilot Study}

\begin{tabular}{|c|c|c|}
\hline Newspaper & $\begin{array}{l}\text { 1=Cape Times } \\
2=\text { Cape Argus }\end{array}$ & $\begin{array}{l}\text { 3=West Cape News } \\
4=\text { Daily Voice }\end{array}$ \\
\hline Date & \multicolumn{2}{|c|}{ date of published article (format=dd/mm/yy) } \\
\hline Length & \multicolumn{2}{|c|}{ Length of written article (format= actual number of words) } \\
\hline ArticleID & \multicolumn{2}{|c|}{ Each article given a number starting with $00 \#$} \\
\hline Themes & Descriptive Words & Number of descriptive words in article \\
\hline $\begin{array}{l}\text { ThemeList1 } \\
\text { ThemeList } 2 \\
\text { ThemeList } 3 \\
\text { ThemeList4 } \\
\text { ThemeList5 } \\
\text { ThemeList6 }\end{array}$ & Article Themes & $\begin{array}{l}1=\text { dark } \\
2=\text { pipe } \\
3=\text { deeply saddened } \\
4=\text { pandemic/epidemic } \\
5=\text { shocking } \\
6=\text { destroying lives } \\
7=\text { scourge } \\
8=\text { abuse } \\
9=\text { recovery } \\
10=\text { homeless } \\
11=\text { risky sexual behavior } \\
12=\text { risk of HIV/AIDS } \\
13=\text { aggression } \\
14=\text { violence } \\
15=\text { odorless substance } \\
16=\text { smoked in glass pipe/light bulb } \\
17 \text {-snorted } \\
18=\text { swallowed } \\
19=\text { injected } \\
20=\text { highly addictive } \\
21=\text { other }\end{array}$ \\
\hline
\end{tabular}

Main theme ID

Personable/emotive

$1=$ Yes

$0=\mathrm{No}$

Scientific/logical

$1=$ Yes

$0=\mathrm{No}$

Neutral

$1=$ Yes

$0=\mathrm{No}$ 


\begin{tabular}{|c|c|c|}
\hline Article & Sub Theme ID & $\begin{array}{l}\text { 1=personable/emotive } \\
2=\text { scientific/logical } \\
3=\text { neutral } \\
\text { 4=unclear }\end{array}$ \\
\hline Contact & Contact Info included & $\begin{array}{l}1=\text { yes } \\
0=\text { no }\end{array}$ \\
\hline Dr.Rx & Physician of treatment facility & $\begin{array}{l}1=\text { Yes } \\
0=\text { No }\end{array}$ \\
\hline Dr.RxPlace & Where in the article & $\begin{array}{l}1=\text { within } \\
2=\text { end } \\
9=\text { missing }\end{array}$ \\
\hline SeekHelp & Help Seeking placement & $\begin{array}{l}1=\text { contact number } \\
2=\text { Physical Address } \\
3=\text { Person and contact detail } \\
9=\text { missing }\end{array}$ \\
\hline AddNum & Percentage of Addiction & $\begin{array}{l}1=\text { Increase } \\
2=\text { decrease } \\
3=\text { no change } \\
4=\text { not mentioned }\end{array}$ \\
\hline$\%$ & number in percentage & $9=$ missing \\
\hline RCHStudy & research studies cited & $\begin{array}{l}1=\text { yes } \\
0=\text { no }\end{array}$ \\
\hline InfoID & $\begin{array}{l}\text { user gender/race/age } \\
9=\text { none listed throughout article }\end{array}$ & \\
\hline InfoIDgen & & $\begin{array}{l}1=\text { yes } \\
0=\text { no }\end{array}$ \\
\hline
\end{tabular}


InfoIDRac

$1=$ yes

$0=$ no

InfoIDage

$1=$ yes

$0=$ no

Gender information of main user

$1=$ male

$2=$ female

$3=$ both genders

$0=$ not listed

PregnantMain information of main user

$1=$ yes

$0=$ no

$9=$ not mentioned

Race

information of main user

$1=$ Black

$2=$ White

$3=$ Colored

4=Indian

$9=$ not mentioned

Age

listed age of user

$1=10-15$ years

$2=16-20$ years

$3=21-26$ years

$4=27-32$ years

$5=33-38$ years

$6=39$ and over

$9=$ not listed

Gender information of other user

PrengantOther information of other user

$$
\begin{aligned}
& 1=\text { male } \\
& 2=\text { female } \\
& 3=\text { both genders } \\
& 9=\text { not listed }
\end{aligned}
$$

$1=$ yes

$0=$ no

$9=$ not mentioned 
Race

Age

listed age of other user

Of user

Photo

Surroundings picture of the surroundings of user

Geographic physical place of user listed

GeoAs

how is it described

PolyDrug

other drugs mentioned in article

If no rest coded as "9"

PolyDrugList other drugs mentioned

Alcohol

Tabaco

Marijuana
$1=$ yes

$0=$ no

$1=$ Black

2=White

$3=$ Colored

4=Indian

9=Not Listed

$1=10-15$ years

$2=16-20$ years

$3=21-26$ years

$4=27-32$ years

$5=33-38$ years

$6=39$ and over

$9=$ not listed

$1=$ yes

$0=$ no

$1=$ yes

$0=$ no

$1=$ yes

$0=$ no

$1=$ hot spot

$2=$ main area

$3=$ distribution hub

4=hardest hit

$5=$ other

$9=$ missing

$1=$ yes

$0=$ no

$1=$ yes

$0=$ no

$1=$ yes

$0=$ no 
Mandrax

$1=$ yes

$0=$ no

Other

$1=$ yes

$0=$ no

VicPrior prior victimization listed

$1=$ yes

$0=$ no

CrimPrior prior criminal activity

$1=$ yes

$0=$ no

ActivityList what activity listed

$$
\begin{aligned}
& 1=\text { prostitution } \\
& 2=\text { theft } \\
& 3=\text { robbery } \\
& 4=\text { violent crime } \\
& 5=\text { nonviolent/other } \\
& 9=\text { missing }
\end{aligned}
$$

ComQuote comments/quotes in article

$1=$ yes

$0=$ no

If no rest coded as "9"

\section{ComQuoteList}

User

$$
\begin{aligned}
& 1=\text { yes } \\
& 0=\text { no }
\end{aligned}
$$

Political Figure

$1=$ yes

$0=$ no

Police Officer

$1=$ yes

$0=$ no

Specialized Task Force

$$
\begin{aligned}
& 1=\text { yes } \\
& 0=\text { no }
\end{aligned}
$$


Community Member

$1=$ yes

$0=$ no

Medical Dr. /Researcher

$1=$ yes

$0=$ no

Other

$$
\begin{aligned}
& 1=\text { yes } \\
& 0=\text { no }
\end{aligned}
$$




\section{Pilot Study Collection Sheet}

Newspaper: Cape Time Cape Argus
West Cape News Daily Voice
IOL
\begin{tabular}{|l|l|}
\hline Date (dd/mm/yy) & Length of Article \\
\hline
\end{tabular}
\begin{tabular}{|l|l|}
\hline Personable/ emoticle ID (00\#) \\
\hline "Dark" & Scientific/ logical \\
\hline "Pipe" & Risky Sexual Behavior \\
\hline "Deeply Saddened" & Risk Of HIV/AIDS \\
\hline "Pandemic/Epidemic" & Violence \\
\hline "Shocking" & Odorless Substance \\
\hline "Destroying Lives" & Smoked In Glass Pipe/Light Bulb \\
\hline "Scourge" & Snorted \\
\hline "Abuse" & Swallowed \\
\hline "Recovery" & Injected \\
\hline "Homeless" & Highly Addictive \\
\hline
\end{tabular}

Main theme ID

\begin{tabular}{|l|l|l|}
\hline Personable/emotive & Scientific/logical & Neutral \\
\hline
\end{tabular}

Sub theme ID

\begin{tabular}{|l|l|l|}
\hline Personable/emotive & Scientific/logical & Neutral \\
\hline
\end{tabular}

Any contact information included?

$$
\begin{array}{|l|l|}
\hline \text { yes } & \text { no } \\
\hline
\end{array}
$$

Physician or treatment facilities listed (Dr. Rx)

$$
\begin{array}{|l|l|}
\hline \text { Yes } & \text { No } \\
\hline
\end{array}
$$


Within article or end of article or none listed?

Where and how to seek help

\section{\begin{tabular}{|l|l|l|} 
Contact number & Physical address & Person and contact details listed \\
\hline
\end{tabular}}

Addiction by Numbers

\begin{tabular}{|l|l|l|l|}
\hline Increase & Decrease & No change & Not mentioned \\
\hline
\end{tabular}

Number in percentage

Research studies cited

Identifying information pertaining to main user

\begin{tabular}{|l|l|l|l|l|l|}
\hline Gender & Race & Photo & Surroundings & Age & Pregnant \\
\hline & & & & & \\
& & & & & \\
& & & & & \\
& & & & & \\
\hline
\end{tabular}

Identifying information pertaining to other user

\begin{tabular}{|l|l|l|l|}
\hline Gender & Race & Age & Pregnant \\
\hline & & & \\
& & & \\
& & & \\
& & & \\
\hline
\end{tabular}

Geographical area listed in article

$$
\begin{array}{|l|l|}
\hline \text { Yes } & \text { No } \\
\hline
\end{array}
$$

Geographical area 
Described as:

\begin{tabular}{|l|l|l|l|l|}
\hline 'hot spot' & 'main area' & 'distribution hub' & 'hardest hit' & 'other' \\
\hline
\end{tabular}

Write 'other' here

Poly-drug use alluded to:

\begin{tabular}{|l|l|}
\hline Yes & No \\
\hline
\end{tabular}

\begin{tabular}{|l|l|l|l|l|}
\hline Alcohol & Tabaco & Marijuana & Mandrax & Other \\
\hline
\end{tabular}

Prior victimization listed in article?

Prior criminal activity listed in article?

Comments or quotes included in article

$$
\begin{array}{|l|l|}
\hline \text { Yes } & \text { No } \\
\hline
\end{array}
$$

\begin{tabular}{|l|l|l|l|l|l|l|}
\hline User & $\begin{array}{l}\text { Political } \\
\text { figure }\end{array}$ & $\begin{array}{l}\text { Police } \\
\text { officer }\end{array}$ & $\begin{array}{l}\text { Specialized } \\
\text { task force }\end{array}$ & $\begin{array}{l}\text { Community } \\
\text { member }\end{array}$ & $\begin{array}{l}\text { Medical } \\
\text { Doctor or } \\
\text { researcher }\end{array}$ & Other \\
\hline
\end{tabular}

Other significant information (2-3 sentences 
APPENDIX B

FINAL STUDY CODE FORM AND COLLECTION SHEET 


\section{Codebook}

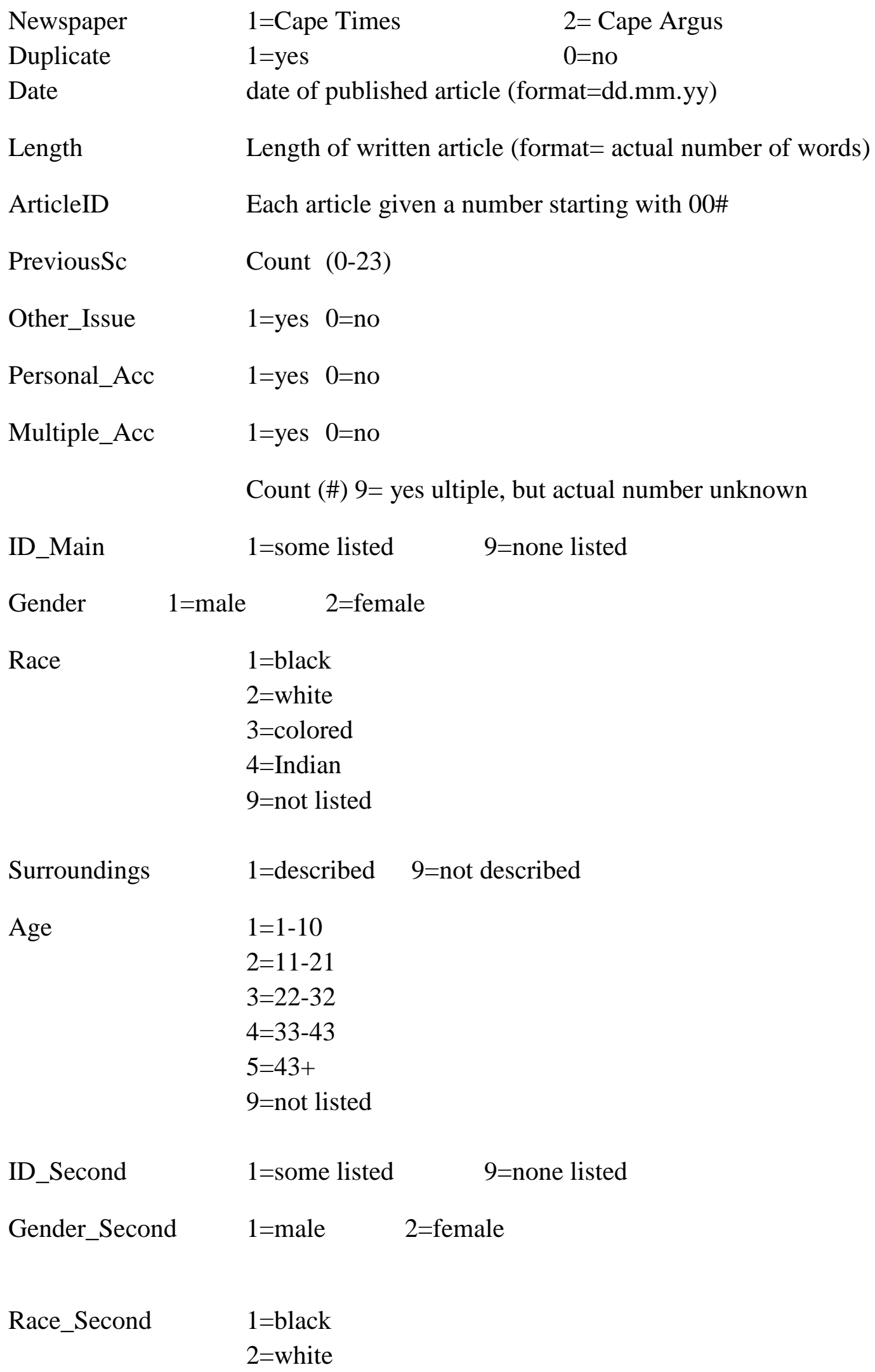


$3=$ colored

4=Indian

9=not listed

$\begin{array}{ll}\text { Surroundings_Sec } & 1=\text { described } 9=\text { not described } \\ \text { Age_Second } & 1=1-10 \\ 2 & =11-21 \\ 3 & =22-32 \\ 4 & =33-43 \\ 5 & =43+ \\ 9 & =\text { not listed }\end{array}$

Tik_Described Write out (string data) "9"=missing

$\begin{array}{lll}\text { Addict_main } & \text { Write out } & \text { " } 9 "=\text { missing } \\ \text { Addict_secondary } & \text { Write out } & \text { " } 9 \text { =missing } \\ \text { Criminal_Activity } & 1=\text { yes } 0=\text { no } \\ & \text { If NO rest coded as "9" } \\ \text { Bust } & 1=\text { yes } 0=\text { no } \\ \text { Raid } & 1=\text { yes } 0=\text { no } \\ \text { Manufacturing } 1=y e s & 0=\text { no } \\ \text { Distribution } & 1=\text { yes } 0=\text { no } \\ \text { Gang_rel } & 1=\text { yes } 0=\text { no } \\ \text { Gang_name } & 1=\text { yes } 9=\text { not listed }\end{array}$

Number_arrest $1=1-5$

$$
\begin{aligned}
& 2=6-10 \\
& 3=11-15 \\
& 4=15+ \\
& 9=\text { not listed }
\end{aligned}
$$

Drugs_Seized 1=tik

$2=$ heroin

$3=$ Cocaine

4=marijuana 


$$
\begin{aligned}
& 5=\text { Mandrax } \\
& 6=\text { other } \\
& 9=\text { unlisted }
\end{aligned}
$$

Amount_Rands $\quad \begin{aligned} & 1=\text { hundreds } \\ & 2=\text { thousands } \\ & 3=\text { millions } \\ & 4=\text { undisclosed } \\ & 9=\text { unlisted }\end{aligned}$

Amount_Value Write out "9"=missing

ComQuote comments/quotes in article 1=yes

$0=$ no

If no rest coded as "9" (main and secondary)

Com_Main

$1=$ User

2=Political Figure

$3=$ Police Officer

4=Specialized Task Force

5=Community Member

6=Medical Dr. /Researcher

$7=$ Other
Com_Secondary $\quad 1=$ User
2=Political Figure
$3=$ Police Officer
4=Specialized Task Force
5=Community Member
6=Medical Dr. /Researcher
$7=$ Other

Tone_Article

Emotional Emo_<descriptive> descriptive words illicit emotional response count $(0-?)$

$\begin{array}{lll}\text { dark } & \text { scourge } & 1=\text { yes } 0=\text { no } \\ \text { pipe } & \text { abuse } & \\ \text { deeply saddened } & \text { recovery } & \\ \text { pandemic/epidemic } & \text { homeless } \\ \text { shocking } & \text { widespread } \\ \text { destroying lives } & \text { infested }\end{array}$




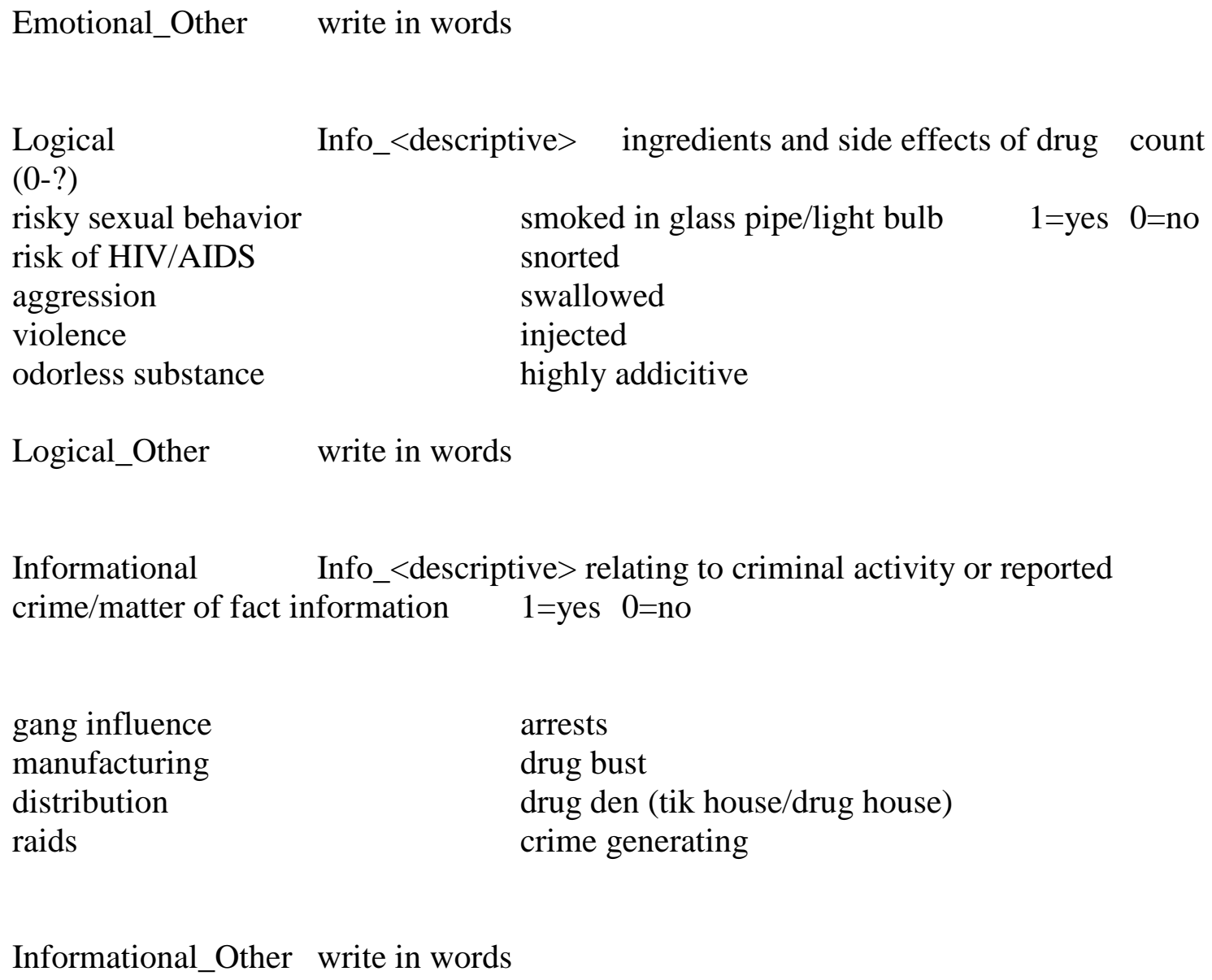

Informational_Other_write in words

Main theme ID

Emotional

$$
\begin{aligned}
& 1=\text { Yes } \\
& 0=\text { No } \\
& 1=\text { Yes } \\
& 0=\text { No } \\
& 1=\text { Yes } \\
& 0=\text { No }
\end{aligned}
$$

Logical

Informational

Article

Sub Theme ID

$1=$ emotional

$2=$ Logical

$3=$ informational 
Percentage_TikUse

Tik_Addiction

People_Using

People_treatment

Geographical_Area

manufacture/distrib

PolyDrug

Drugs_1

Drugs_2

Described_As number in $\% \quad 9=$ missing

Addiction figures stated

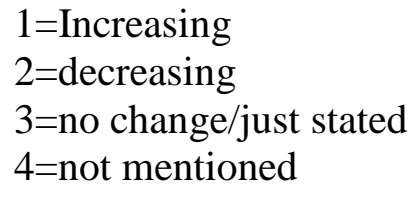

$\begin{array}{ll}\text { number }(\%) & \begin{array}{l}1=\text { yes } \\ 0=\text { no }\end{array} \\ \text { number }(\%) & \begin{array}{l}1=\text { yes } \\ 0=\text { no }\end{array}\end{array}$

Physical Place

1=Athlone

$$
1=\text { yes } 0=\text { no }
$$$$
\text { 2=Manenburg }
$$

3=Elsies River

4=Delft

$5=$ Ravensmead

$6=$ Kleinvlei

$7=$ Kuilsriver

$8=$ Kraaifontein

9=Mitchells Plain

$10=$ Cape Town central

$11=$ Other

99=not listed

Geographical_AreaOther write in other

$1=$ hot spot

$2=$ main area

$3=$ distribution hub

4=hardest hit

$5=$ place of

$6=$ other (write out)

$9=$ not described

$1=$ yes

$0=$ no

If no rest coded as "9" 
Drugs_3

Drugs_Other write out

RCHStudy research studies cited

Dr.Rx

Physician of treatment facility

Contact_Info Contact Info included

SeekHelp Help Seeking placement

Info_Place Where in the article
$1=$ alcohol

$2=$ tobacco

$3=$ marijuana

4=Mandrax

$5=$ other (write out)

$9=$ not mentioned

$9=\operatorname{missing}$

$1=$ yes

$0=$ no

$1=$ Yes

$0=\mathrm{No}$

$1=$ yes

$0=$ no

$1=$ contact number

2=Physical Address

$3=$ Person and contact detail

$9=$ missing

1=within

$2=$ end

$9=$ missing 
Newspaper: $\quad$ Cape Time Cape Argus

Duplicate article $\quad$ Yes No

\section{\begin{tabular}{|l|l|l|}
\hline Date $(\mathrm{dd} / \mathrm{mm} / \mathrm{yy})$ & Length of Article & Article ID (00\#) \\
\hline
\end{tabular}}

Words used in previous scares:

Widespread

Tidal wave of substance abuse

Infested

Plague

Pervasive

Crime generating

Universal

Wave

Cheaper than cocaine

$\begin{array}{ll}\text { new drug of choice } & \text { unprecedented } \\ \text { tik head (meth head) } & \text { scourge } \\ \text { tik mouth (meth mouth) } & \text { ravage } \\ \text { tik baby (crack baby) } & \begin{array}{l}\text { demon drug } \\ \text { crisis }\end{array} \\ \text { instant addiction } & \\ \text { sweeping the country } & \\ \text { terrifying } & \\ \text { dangerous } & \\ \text { threatening } & \end{array}$

Does this article mention tik in relation to other issues? (E.g. letter to the editor, personal rant of general displeasure of society) Yes No

Is this article a personal account of tik or a tik addict? Yes No Are there multiple accounts of tik or a tik addict? $\quad$ Yes No \# Identifying information pertaining to main user (main focus)

\begin{tabular}{|l|l|l|l|l|}
\hline Gender & Race & Surroundings & Age & Pregnant \\
\hline & & & & \\
& & & & \\
& & & & \\
\hline
\end{tabular}

Identifying information pertaining to secondary user (secondary focus)

\begin{tabular}{|l|l|l|l|l|}
\hline Gender & Race & Surroundings & Age & Pregnant \\
\hline & & & & \\
& & & & \\
& & & & \\
& & & & \\
\hline
\end{tabular}

Tik described as: 
Addict (main) described as:

Addict (secondary) described as:

Does this article describe criminal activity related to tik? $\quad$ Yes No

\begin{tabular}{|c|c|c|c|c|c|}
\hline $\begin{array}{l}\text { Drug } \\
\text { bust }\end{array}$ & $\begin{array}{l}\text { Drug } \\
\text { raid }\end{array}$ & Manufacturing & Distribution & $\begin{array}{l}\text { Gang } \\
\text { related }\end{array}$ & $\begin{array}{l}\text { Number of people } \\
\text { arrested }\end{array}$ \\
\hline $\begin{array}{l}\text { Yes } \\
\text { No }\end{array}$ & $\begin{array}{l}\text { Yes } \\
\text { No }\end{array}$ & $\begin{array}{l}\text { Yes } \\
\text { No }\end{array}$ & $\begin{array}{l}\text { Yes } \\
\text { No }\end{array}$ & $\begin{array}{l}\text { Yes } \\
\text { No }\end{array}$ & $\begin{array}{l}1-5 \\
6-10 \\
11-15 \\
15+\end{array}$ \\
\hline
\end{tabular}

\begin{tabular}{|l|l|}
\hline Drugs seized & Amount in Rands \\
\hline Tik & Hundreds \\
Heroine & Thousands \\
Cocaine \\
Marijuana \\
$\begin{array}{l}\text { Mandrax } \\
\text { other }\end{array}$ & Million \\
\hline
\end{tabular}

Comments or quotes included in article

$$
\begin{array}{|l|l|}
\hline \text { Yes } & \text { No } \\
\hline
\end{array}
$$

Main speaker

\begin{tabular}{|c|c|c|c|c|c|c|}
\hline User & $\begin{array}{l}\text { Political } \\
\text { figure }\end{array}$ & $\begin{array}{l}\text { Police } \\
\text { officer }\end{array}$ & $\begin{array}{l}\text { Specialized } \\
\text { task force }\end{array}$ & $\begin{array}{l}\text { Community } \\
\text { member }\end{array}$ & $\begin{array}{l}\text { Medical } \\
\text { Doctor or } \\
\text { researcher }\end{array}$ & Other \\
\hline \multicolumn{7}{|c|}{ Secondary speaker } \\
\hline User & $\begin{array}{l}\text { Political } \\
\text { figure }\end{array}$ & $\begin{array}{l}\text { Police } \\
\text { officer }\end{array}$ & $\begin{array}{l}\text { Specialized } \\
\text { task force }\end{array}$ & $\begin{array}{l}\text { Community } \\
\text { member }\end{array}$ & $\begin{array}{l}\text { Medical } \\
\text { Doctor or } \\
\text { researcher }\end{array}$ & Other \\
\hline
\end{tabular}


The tone of the article

\begin{tabular}{|l|l|l|}
\hline Emotional & Logical & Informational \\
\hline dark & risky sexual behavior & gang influence \\
\hline pipe & risk of HIV/AIDS & manufacturing \\
\hline deeply saddened & aggression & distribution \\
\hline pandemic/epidemic & violence & raids \\
\hline shocking & odorless substance & arrests \\
\hline destroying lives & smoked in glass pipe/light bulb & drug bust \\
\hline scourge & snorted & drug den \\
\hline abuse & swallowed & crime generating \\
\hline recovery & injected & \\
\hline homeless & highly addictive & \\
\hline widespread & & \\
\hline infested & & \\
\hline
\end{tabular}

Main theme ID

\begin{tabular}{|l|l|l|l|}
\hline emotional & logical & informational & \\
\hline
\end{tabular}

Sub theme ID

\begin{tabular}{|l|l|l|l|}
\hline emotional & logical & informational \\
\hline
\end{tabular}

Addiction by numbers:

Number in percentage: related to tik use or abuse

Tik described as:

\begin{tabular}{|l|l|l|l|}
\hline Increasing & Decreasing & No change/just stated & Not mentioned \\
\hline
\end{tabular}

Number of people using tik mentioned: $\quad$ Yes No

Number in (percent)

Number of people seeking treatment mentioned: $\quad$ Yes $\quad$ No

Number in (Percent)

Geographical area listed?

Yes

No

1. Athlone

2. Manenberg 
3. Elsies River

4. Delft

5. Ravensmead

6. Kleinvlei

7. Kuilsriver

8. Kraaifontein

9. Mitchells Plain

10. Cape Town Central

11. Other?

Described as:

\begin{tabular}{|l|l|l|l|l|} 
hot spot & main area & distribution hub & hardest hit & Place of manufacturing/distributer \\
\hline
\end{tabular}

Other

Poly-drug use alluded to:

Yes 1 No

\begin{tabular}{|l|l|l|l|l|}
\hline Alcohol & Tabaco & Marijuana & Mandrax & Other \\
\hline
\end{tabular}

Other

Research studies cited: Yes or No

\begin{tabular}{|l|l|}
\multicolumn{2}{|c}{ Physician or treatment facilities listed (Dr. Rx) } \\
\hline Yes & No \\
\hline
\end{tabular}

Any contact information included?

$$
\begin{array}{|l|l|}
\hline \text { yes } & \text { no } \\
\hline
\end{array}
$$

Where and how to seek help

\begin{tabular}{|l|l|l|}
\hline Contact number & Physical address & Person and contact details listed \\
\hline
\end{tabular}

Within article or end of article or none listed?

Other significant information (2-3 sentences) 